OPEN ACCESS

Edited by:

Jingwen Zhou,

Jiangnan University, China

Reviewed by:

Kohsuke Honda,

Osaka University, Japan

Leonardo Rios Solis,

University of Edinburgh,

United Kingdom

*Correspondence:

Yong Wang

yongwang@cemps.ac.cn

Specialty section: This article was submitted to

Synthetic Biology,

a section of the journal Frontiers in Bioengineering and

Biotechnology

Received: 22 November 2020

Accepted: 11 January 2021

Published: 05 February 2021

Citation:

Mutanda I, Li J, Xu F and Wang Y (2021) Recent Advances in Metabolic Engineering, Protein Engineering, and Transcriptome-Guided Insights Toward Synthetic Production of Taxol. Front. Bioeng. Biotechnol. 9:632269. doi: 10.3389/fbioe.2021.632269

\section{Recent Advances in Metabolic Engineering, Protein Engineering, and Transcriptome-Guided Insights Toward Synthetic Production of Taxol}

\author{
Ishmael Mutanda ${ }^{1}$, Jianhua $\mathrm{Li}^{1}$, Fanglin $\mathrm{Xu}^{1,2,3}$ and Yong Wang ${ }^{1 *}$ \\ 1 Key Laboratory of Synthetic Biology, CAS Center for Excellence in Molecular Plant Sciences, Institute of Plant Physiology \\ and Ecology, Chinese Academy of Sciences, Shanghai, China, ${ }^{2}$ University of Chinese Academy of Sciences, Beijing, China, \\ ${ }^{3}$ Key Laboratory of Plant Stress Biology, State Key Laboratory of Cotton Biology, School of Life Sciences, He'nan University, \\ Kaifeng, China
}

The diterpenoid paclitaxel $\left(\operatorname{Taxol}^{\circledR}\right)$ is a blockbuster anticancer agent that was originally isolated from the Pacific yew (Taxus brevifolia) five decades ago. Despite the wealth of information gained over the years on Taxol research, there still remains supply issues to meet increasing clinical demand. Although alternative Taxol production methods have been developed, they still face several drawbacks that cause supply shortages and high production costs. It is highly desired to develop biotechnological production platforms for Taxol, however, there are still gaps in our understanding of the biosynthetic pathway, catalytic enzymes, regulatory and control mechanisms that hamper production of this critical drug by synthetic biology approaches. Over the past 5 years, significant advances were made in metabolic engineering and optimization of the Taxol pathway in different hosts, leading to accumulation of taxane intermediates. Computational and experimental approaches were leveraged to gain mechanistic insights into the catalytic cycle of pathway enzymes and guide rational protein engineering efforts to improve catalytic fitness and substrate/product specificity, especially of the cytochrome P450s (CYP450s). Notable breakthroughs were also realized in engineering the pathway in plant hosts that are more promising in addressing the challenging CYP450 chemistry. Here, we review these recent advances and in addition, we summarize recent transcriptomic data sets of Taxus species and elicited culture cells, and give a bird'seye view of the information that can be gleaned from these publicly available resources. Recent mining of transcriptome data sets led to discovery of two putative pathway enzymes, provided many lead candidates for the missing steps and provided new insights on the regulatory mechanisms governing Taxol biosynthesis. All these inferences are relevant to future biotechnological production of Taxol.

Keywords: Taxol, protein engineering, transcriptome, paclitaxel, taxadien- $5 \alpha-$ ol, taxane- $5 \alpha$-hydroxylase, metabolic engineering 


\section{INTRODUCTION}

The blockbuster antitumor drug paclitaxel (Taxol ${ }^{\circledR}$ ) is a highly functionalized plant diterpenoid discovered in the late 1960s in pacific yew (Taxus brevifolia) plants. Though it went through a long developmental phase, it later became the most successful plant natural product in use as an effective chemotherapy drug since its initial Food and Drug Administration (FDA) approval in 1992 (Wani et al., 1971; Wani and Horwitz, 2014). Taxol was initially approved for treatment of refractory ovarian cancer and breast carcinomas, but over the years it has found expanded clinical uses in treatment of non-small cell lung carcinoma, Kaposi's sarcoma and cancers of the lung, breast, bladder, prostate, esophagus and pancreas when used alone or in combination therapies with other antineoplastic agents.

Original production process involved direct isolation from the bark of yew plants, but the process is very destructive and inefficient, requiring three trees $(\sim 12 \mathrm{~kg}$ bark material $)$ to produce $1 \mathrm{~g}$ pure Taxol or ca. 3,000 yew trees to produce only $1 \mathrm{~kg}$ of the drug (Malik et al., 2011; McElroy and Jennewein, 2017). To add to this, Taxol is produced as a complex mixture with hundreds of other taxanes in Taxus plant tissue, making the purification of this highly hydrophobic compound very laborious and environmentally damaging due to use of organic solvents (Wani and Horwitz, 2014). Total chemical synthesis routes to Taxol were developed (Holton et al., 1994; Nicolaou et al., 1994), but are not commercially viable owing to the many steps required and cost considerations. Inspired by the success of Taxol, and the need to address supply and ecological challenges, alternative production platforms have been developed: (i) extraction of 10-deacetylbaccatin III (10-DAB) or baccatin III (BIII) from renewable twigs of Taxus species, that can be semi-synthetically modified to Taxol, and (ii) plant cell fermentation (PCF) involving use of Taxus cell suspension cultures (Fett-Netto et al., 1992; Mountford, 2010; Malik et al., 2011).

Despite several optimization efforts to improve these methods, they still suffer from several drawbacks that limit their capacity and also drive the price of Taxol high; (i) production from twigs is still dependent on yew trees, thus is susceptible to weather and environmental factors, (ii) long maturity time of the trees and (iii) extraction process still involves use of organic solvents. The PCF route presents obvious advantages over direct extraction from field-grown Taxus twigs, but it suffers from its own shortcomings; (i) instability of cell lines in the long fermentation periods (ii) use of endogenous biosynthetic pathways, thus no genetic engineering targets to improve flux toward Taxol and (iii) poor Taxol yields in the fermenters, even with elicitors (Choi et al., 2000; Ketchum and Croteau, 2006).

For these reasons, it is highly desirable to establish biotechnological production systems for Taxol production that will address most of these issues. Production in more amenable, fast-growing heterologous hosts offers more advantages in terms of control and manipulation of metabolic flux by improving enzyme expression, pathway regulation, availability of cofactors and engineering competing pathways. However, there are challenges that prevent development of desired sustainable Taxol biotechnological platforms: the biosynthetic pathway is long and complicated, involving 19 expected steps from geranylgeranyl diphosphate (GGPP) the universal precursor of diterpenoids (Figure 1) and there are still many gaps in our understanding of Taxol biosynthesis and its regulatory mechanisms. Several cytochrome P450 (CYP450) hydroxylases and an epoxidase remain missing (Figure 1). Even for the steps with known enzymes, expression of functional pathway enzymes in heterologous hosts, especially the CYP450s is proving to be non-trivial.

In this review, we discuss various strategies conducted in the last 5 years to develop heterologous systems for Taxol biosynthesis. Building from the breakthrough strategy 10 years ago (Ajikumar et al., 2010), recent advances in synthetic biology have been applied in several studies to optimize pathway expression, develop enzyme screening platforms and engineer pathway enzymes to get variants with improved catalytic performance and higher specificity. We also highlight the use of computational tools that were leveraged in gaining insights in the catalytic mechanisms of several enzymes and lastly, we summarize recent Taxol-related transcriptomes and how this publicly available resource was recently used in inferring regulatory mechanisms, mining the missing genes and providing many lead candidates for missing steps. In the coming years, we expect this knowledge to be pivotal in development of biotechnological systems for production of this critical drug.

\section{CHALLENGES WITH METABOLIC ENGINEERING OF TAXOL PATHWAY}

Metabolic engineering of the Taxol pathway in heterologous hosts is highly desirable as it will establish a versatile, direct route to the critical anticancer drug. Biosynthetic production systems are expected to improve supply of Taxol, as well as lower the production costs through improved efficiency and use of inexpensive sugars as starting material in microbial factories. Another potential avenue under exploration is production in cheaper, high biomass and fast-growing plants like tobacco that can be engineered for high-level production of non-native metabolites using carbon resources from photosynthesis. Before realizing this dream, there are several challenges with Taxol biosynthesis that should be addressed.

\section{The Missing Pathway Enzymes}

Taxol is derived from the $\mathrm{C}_{5}$ terpenoid universal precursors, dimethylallyl diphosphate (DMAPP) and isopentenyl pyrophosphate (IPP) through geranylgeranyl diphosphate (GGDP), the $\mathrm{C}_{20}$ universal precursor of all diterpenoids. The structure of the Taxol molecule is complex and likewise, the biosynthetic pathway is equally complex; five decades after its discovery, the pathway is not yet fully understood, with several steps still undefined, and several enzymes still missing. These gaps in our understanding of the biosynthetic pathway deprive us of the critical framework to manipulate Taxol biosynthesis and develop heterologous production systems. The pathway is hypothesized to involve 19 steps from GGPP 

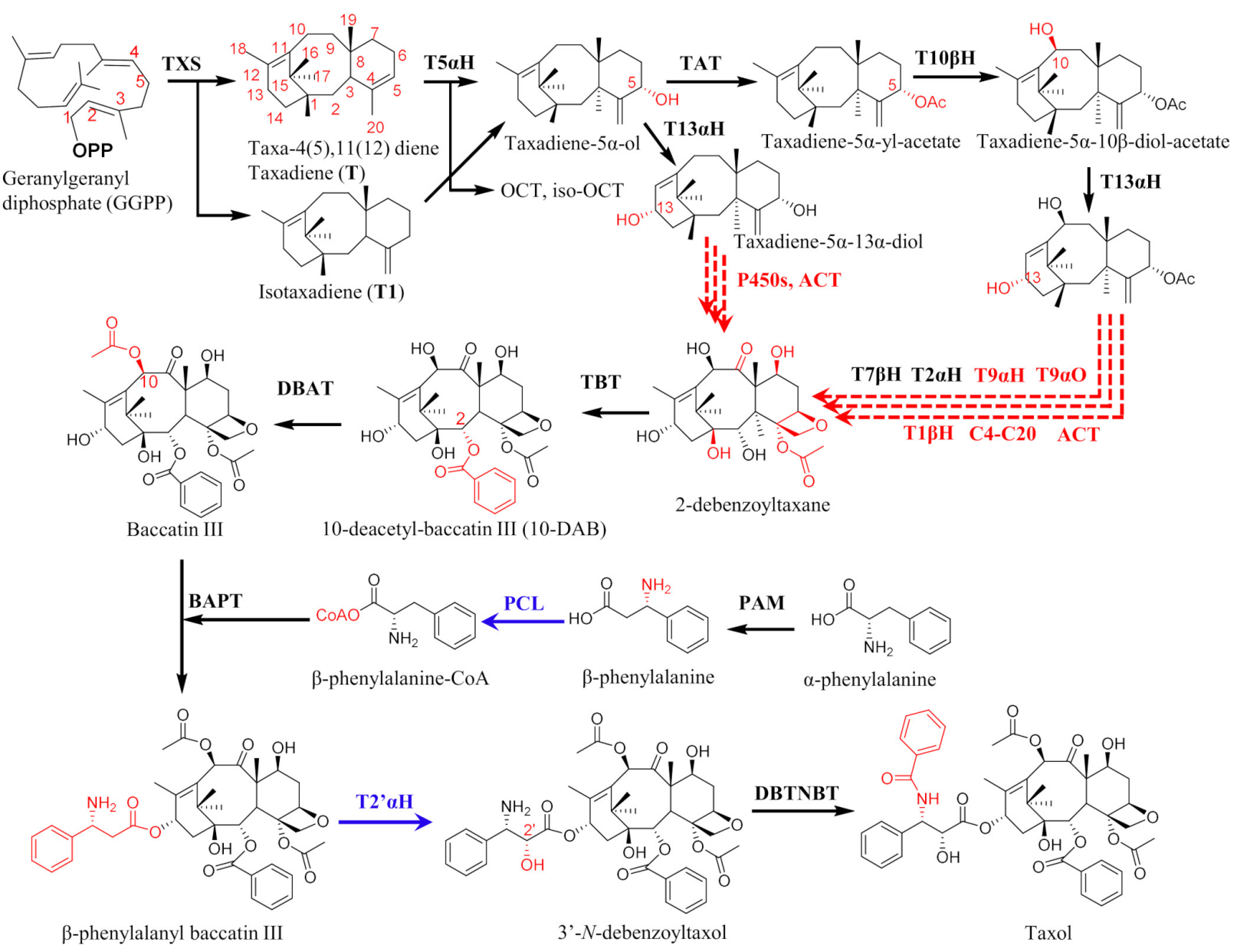

FIGURE 1 | Taxol biosynthetic pathway from geranylgeranyl diphosphate, showing carbon positions. Enzymes in red are not yet characterized and steps in red dotted arrows are not yet fully elucidated. Blue arrows - genes encoding putative PCL and T2' $\alpha \mathrm{H}$ were recently isolated, though not yet applied in metabolic engineering designs. Enzyme abbreviations: TXS, taxadiene synthase; T5 $\alpha \mathrm{H}$, taxane-5 $\alpha$-hydroxylase; TAT, taxane-5 $\alpha$-ol-O-acetyltransferase; T10 $\beta \mathrm{H}$,

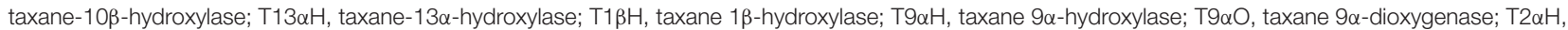
taxane $2 \alpha$-hydroxylase; T7 $\beta \mathrm{H}$, taxane $7 \beta$-hydroxylase; C4-C20, C4-C20 epoxidase; TBT, taxane-2 $\alpha$-O-benzoyl transferase; DBAT, 10-deacetylbaccatin III-10-O-acetyltransferase; PAM, phenylalanine aminomutase; PCL, phenylalanine-CoA ligase; BAPT, C-13 phenylpropanoyl-CoA transferase; T2' $\alpha \mathrm{H}$, taxane $2^{\prime} \alpha$-hydroxylase; DBTNBT, Debenzoyl taxol N-benzoyl transferase. Products of T5aH-OCT, 5(12)-oxa-3 (11)-cyclotaxane and iso-OCT, 5(13)-oxa-3(11)-cyclotaxane, ACT, acyl-CoA transferase.

(Figure 1), involving terpene cyclization, 9 cytochrome P450catalyzed hydroxylations, 3 acylations, acetylations, oxetane ring formation, benzoylations, and phenylisoserine side chain attachment. Exceptional work in the last 25 years has contributed genes and enzymes of up to 14 steps; from taxadiene synthase (TXS) that catalyzes the first and committed step to cyclize GGPPS to taxadiene (Hezari et al., 1995; Wildung and Croteau, 1996), five CYP450s [taxane $5 \alpha$-hydroxylase $(\mathrm{T} 5 \alpha \mathrm{H})$, taxane $2 \alpha$-hydroxylase $(\mathrm{T} 2 \alpha \mathrm{H})$, taxane $7 \beta$-hydroxylase $(\mathrm{T} 7 \beta \mathrm{H})$, taxane $10 \beta$-hydroxylase $(\mathrm{T} 10 \beta \mathrm{H})$ and taxane $13 \alpha$-hydroxylase $(\mathrm{T} 13 \alpha \mathrm{H})]$ (Hefner et al., 1996; Jennewein et al., 2001; Kaspera and Croteau, 2006; Schoendorf et al., 2001; Walker et al., 2000; Walker and Croteau, 2001), five acyl CoA transferases (ACTs) [taxane-5 $\alpha$-olO-acetyltransferase (TAT), taxane-2 $\alpha$-O-benzoyl transferase (TBT), 10-deacetylbaccatin III-10-O-acetyltransferase (DBAT), C-13 phenylpropanoyl-CoA transferase (BAPT) and Debenzoyl taxol $N$-benzoyl transferase (DBTNBT)] and phenylalanine aminomutase (PAM).

A putative ACT that activates $\beta$-phenylalanine to $\beta$-phenylalanine-CoA was isolated from $T$. baccata cell cultures (Ramírez-Estrada et al., 2016), and was identified as $\beta$-phenylalanine-CoA ligase (PCL) after functional characterization. However, a recently isolated homolog of this PCL displaying 99\% sequence identity showed no detectable activity against both $\beta$-phenylalanine and 3-phenylisoserine in vitro (Srividya et al., 2020), thus, the suitability of this clone for heterologous expression in other hosts might remain an open question. Other still missing enzymes are the CYP450s taxane $1 \beta$-hydroxylase $(\mathrm{T} 1 \beta \mathrm{H})$, taxane $9 \alpha$-hydroxylase $(\mathrm{T} 9 \alpha \mathrm{H})$, taxane $9 \alpha$-oxidase $(\mathrm{T} 9 \alpha \mathrm{O})$, and $\mathrm{C} 4,5$ epoxidase (Figure 1). Taxane $2^{\prime} \alpha$-hydroxylase $\left(\mathrm{T} 2^{\prime} \alpha \mathrm{H}\right)$ was recently isolated from mining T. baccata transcriptome (Sanchez-Muñoz et al., 2020), and the 
details are reviewed in the section on transcriptomes below. The missing enzymes, together with other challenges outlined below need to be resolved before successful production of Taxol by synthetic biology systems. Other enzymes have been identified that channel flux toward off-pathway intermediates that do not lead to Taxol, such as the taxane $14 \beta$-hydroxylase $(\mathrm{T} 14 \beta \mathrm{H})$, the recently discovered ACTs that attach different groups to $3^{\prime}$-N-debenzoyltaxol (Srividya et al., 2020) and many more that are expected considering the chemical diversity of taxanes in plant tissues.

\section{Poor Expression of Functional Enzymes and Challenges in CYP450 Chemistry}

Oxygenation chemistry of Taxol presents a formidable barrier to both pathway elucidation and metabolic engineering efforts, starting with the first hydroxylation of the C5 position of taxadiene by T5 $\alpha \mathrm{H}$ (Hefner et al., 1996; Jennewein et al., 2004). All Taxus CYP450s identified and functionally characterized for activity in Taxol biosynthesis are from the CYP725A subfamily, including $\mathrm{T} 5 \alpha \mathrm{H}$ (CYP725A4). T5 $\alpha \mathrm{H}$ accepts both taxa-4(5),11(12) diene (taxadiene, $\mathbf{T}$ ) and its close alternative isomer taxa-4(20),11(12) diene (isotaxadiene, T1), that are both products of TXS to form taxadiene- $5 \alpha-\mathrm{ol}$ (T-5 $\alpha$-ol) (Figure 1). This CYP450 presents several challenges due to the fact that it accepts both $\mathbf{T}$ and $\mathbf{T} 1$ as substrates, its inherent product promiscuity, poor expression in heterologous hosts and low catalytic activity (it has been shown to convert less than $10 \%$ of taxadiene to $\mathrm{T}-5 \alpha-\mathrm{ol})$. Most research efforts in the past 5 years were focused on $\mathrm{T} 5 \alpha \mathrm{H}$, and more synthetic biology tools have been dedicated to $\mathrm{T} 5 \alpha \mathrm{H}$ than any other pathway enzyme to overcome this bottleneck on the second step of the pathway, thus, this review also has more comprehensive discussions on this enzyme.

To understand the origin of $\mathrm{T} 5 \alpha \mathrm{H}$ bottleneck, we present its history in heterologous expression in different hosts. Following successful cloning, functional expression and characterization of eight enzymes of the upper segment of the Taxol pathway, DeJong et al. (2006) sought to construct the first five sequential steps of the pathway leading to taxadien-5 $\alpha$-acetoxy-10 $\beta$-ol in yeast (Saccharomyces cerevisiae). Expression and enzyme kinetics of $\mathrm{T} 5 \alpha \mathrm{H}$ in this construct was the lowest compared to other enzymes, leading to the first detection of a bottleneck at this first oxygenation step that restricted flux toward downstream steps. Two years later, an attempt to introduce TXS and $\mathrm{T} 5 \alpha \mathrm{H}$ in wild tobacco (Nicotiana sylvestris), targeting trichomes after knocking down production of cembratrien-diols similarly failed to produce the desired T- $5 \alpha$-ol, but instead led to production of a cyclic ether, 5(12)-oxa-3(11)-cyclotaxane (OCT) (Rontein et al., 2008) (summary of these metabolic engineering constructs are in Table 1). Intrigued by this observation, $\mathrm{T} 5 \alpha \mathrm{H}$ was expressed in yeast in the same study, and again OCT was observed. The bottleneck was again encountered in a carefully optimized Escherichia coli strain that was engineered via a multivariate modular metabolic engineering (MMME) approach that achieved a 15,000-fold increase in taxadiene production (titers of $\sim 1 \mathrm{~g} / \mathrm{L}$ ) but lost optimality and titers on introduction of $\mathrm{T} 5 \alpha \mathrm{H}$ (Ajikumar et al., 2010). Recent studies corroborated lack of selectivity and product promiscuity of $\mathrm{T} 5 \alpha \mathrm{H}$ in vitro and in several heterologous hosts like E. coli, S. cerevisiae, Yarrowia lipolytica, and Nicotiana benthamiana, showing a product profile dominated by OCT and its close isomer, iso-OCT, with T$5 \alpha$-ol and several other monooxygenated diterpenes as minor compounds (Yadav, 2014; Biggs et al., 2016a,b; Edgar et al., 2016; Sagwan-Barkdoll and Anterola, 2017; Li et al., 2019). A number of optimization and engineering strategies that leveraged advances in synthetic biology have been applied to overcome the $\mathrm{T} 5 \alpha \mathrm{H}$ bottleneck as discussed in the sections below.

\section{Poor Pathway Flux and the Branched Nature of the Pathway}

Despite that much of the Taxol pathway enzymes and genes have been identified, success in engineering at least the known segments of the pathway in heterologous systems have been mainly hampered by inherent poor enzyme catalysis, protein interdependency issues and product promiscuity of key enzymes that lead to a highly branched pathway. Carbon flux is channeled toward off-target products by the promiscuous enzymes, presenting a formidable challenge to synthetic biologists that cannot be solved by simple redirection of IPP and DMAPP precursors. The first enzyme, TXS is now known to have a broad substrate profile including verticillenes and reports of cembrene $\mathrm{A}$, in addition to $\mathbf{T}$ and $\mathbf{T} \mathbf{1}$, as discussed below. The T5 $2 \mathrm{H}$ - catalyzed second step splits $\mathrm{T}$ into many other products, dominated by OCT and its isomer, iso-OCT, branching the pathway into many directions. Several other downstream enzymes also accept different substrates and have broad product profiles, which present an emerging picture of a highly branched pathway. This lack of linearity is at the core of the problems with the pathway that has not only slowed metabolic engineering advances, but has even prevented pathway elucidation and identification of key downstream intermediates. Not surprisingly, recent work has focused on improving the catalytic efficiency and selectivity of pathway enzymes through experimental methods supported by computational tools to improve our mechanistic understanding of catalysis, as covered in the next sections.

\section{Lack of Knowledge on the Regulatory Mechanisms and in planta Transport Mechanisms}

Not much is known on the regulation of the Taxol pathway at transcription, translation and post-translational levels. Elicitors like methyl jasmonate (MeJA) have been used for a relatively long time in improving secondary metabolism in Taxus cell suspension cultures, but the mechanisms through which MeJA activates Taxol biosynthesis have not been elucidated in detail. Knowledge of the regulatory mechanisms, identification of key transcription factors and any feedback loops in the pathway is critical in informing metabolic engineering efforts. Likewise, there are also many gaps in our understanding of the transport mechanisms of taxane intermediates in plant cells. This wealth of information will be very vital in designing a biosynthetic route to Taxol especially in plant cells. 
TABLE 1 | Heterologous production of early taxane metabolites in different platforms.

\begin{tabular}{|c|c|c|c|}
\hline Host & Details & Achievements & References \\
\hline E. coli & $\begin{array}{l}\text { Multivariate-modular metabolic engineering (MMME) } \\
\text { approach to optimize the MEP pathway and } \\
\text { GGPP-TXS as two operons under inducible promoters }\end{array}$ & $\begin{array}{l}\text { Taxadiene accumulation to } 1 \mathrm{~g} / \mathrm{L} \text {. Introduction of } \\
\text { T5 } \alpha \mathrm{H} \text {-CPR disrupted taxadiene balance and achieved } \\
\sim 58 \mathrm{mg} / \mathrm{L} \text { taxadiene- } 5 \alpha \text {-ol and equal amounts of } \\
5(12) \text {-oxa-3(11)-cyclotaxane (OCT) }\end{array}$ & $\begin{array}{l}\text { Ajikumar et al., } \\
2010\end{array}$ \\
\hline E. coli & $\begin{array}{l}\text { TXS and elaborately optimized T5 } \mathrm{HH} \text { and CYP450 } \\
\text { reductase partner optimizations through } \mathrm{N} \text {-terminal } \\
\text { modifications, fusion linked chimera protein expression, } \\
\text { and controlled promoter strength. }\end{array}$ & $\begin{array}{l}\text { Oxygenated taxanes }(570 \mathrm{mg} / \mathrm{L}) \text { was achieved in a } \\
\text { bioreactor }\end{array}$ & $\begin{array}{l}\text { Biggs et al., } \\
2016 a\end{array}$ \\
\hline E. coli & Co-expression of dxs, idi, GGPPS, and TXS & Taxadiene (1.3 mg/L) in shake flask & $\begin{array}{l}\text { Huang et al., } \\
2001\end{array}$ \\
\hline E. coli and S. cerevisiae & $\begin{array}{l}\text { A synthetic consortium was designed and genes for } \\
\text { taxadiene- } 5 \alpha-10 \beta \text {-diol-acetate production were } \\
\text { designed in } 2 \text { modules, taxadiene module in E. coli and } \\
\text { acetylation and CYP450-oxygenation chemistry in } \\
\text { S. cerevisiae for a stable co-culture fermentation using } \\
\text { xylose as carbon source }\end{array}$ & $\begin{array}{l}33 \mathrm{mg} / \mathrm{L} \text { oxygenated taxanes were achieved with TXS } \\
\text { and } \mathrm{T} 5 \alpha \mathrm{H} \text {, and adding } \mathrm{T} 10 \mathrm{BH} \text { and TAT achieved } \\
1.0 \mathrm{mg} / \mathrm{L} \text { of the target monoacylated, dioxygenated } \\
\text { taxane }\end{array}$ & $\begin{array}{l}\text { Zhou et al., } \\
2015\end{array}$ \\
\hline Bacillus subtilis & $\begin{array}{l}\text { Overexpression of all MEP pathway genes ( } d x s \text {, ispD, } \\
\text { ispF, ispH, ispC, ispE, ispG) together with ispA, GGPPS } \\
\text { and TXS }\end{array}$ & $\begin{array}{l}\text { Taxadiene accumulated to } 1.98 \mathrm{mg} / \mathrm{L} / \mathrm{OD}_{600} \\
(17.8 \mathrm{mg} / \mathrm{L}) \text { in shake flask }\end{array}$ & $\begin{array}{l}\text { Abdallah et al., } \\
2019\end{array}$ \\
\hline S. cerevisiae & $\begin{array}{l}\text { Multi-step pathway construction of } 5 \text { taxoid } \\
\text { biosynthetic genes (GGPPS, TXS, T } 5 \alpha \mathrm{H} \text {, TAT, and } \\
\text { T10 } \beta \text { H) to attempt taxadiene- } 5 \alpha \text {-acetoxy-10 } \beta \text {-ol } \\
\text { production. }\end{array}$ & $\begin{array}{l}\text { All } 5 \text { recombinant proteins were successfully expressed } \\
\text { and had measurable activity. Only Taxadiene }(1 \mathrm{mg} / \mathrm{L}) \\
\text { and trace amounts of taxadiene- } 5 \alpha-0 l(\sim 25 \mu \mathrm{g} / \mathrm{L}) \text { was } \\
\text { detected. No advanced metabolites were detected }\end{array}$ & $\begin{array}{l}\text { DeJong et al., } \\
2006\end{array}$ \\
\hline S. cerevisiae & $\begin{array}{l}\text { Heterologous expression of a truncated } \\
\text { 3-hydroxyl-3-methylglutaryl-CoA reductase (tHMGR), a } \\
\text { mutant regulatory protein, UPC2-1, GGPPS from } \\
\text { Sulfolobus acidocaldarius and TXS }\end{array}$ & $\begin{array}{l}\text { Taxadiene }(8.7 \mathrm{mg} / \mathrm{L}) \text { and geranylgeraniol }(33 \mathrm{mg} / \mathrm{L}) \\
\text { accumulated in shake flasks after } 48 \mathrm{~h} \text { fermentations }\end{array}$ & $\begin{array}{l}\text { Engels et al., } \\
2008\end{array}$ \\
\hline S. cerevisiae & $\begin{array}{l}\text { Heterologous TXS and GGPPS (from Taxus cuspidate } \\
\times \text { Taxus baccata) and overexpression of erg20 and } \\
\text { tHMGR }\end{array}$ & Taxadiene accumulated to $72.8 \mathrm{mg} / \mathrm{L}$ & $\begin{array}{l}\text { Ding et al., } \\
2014\end{array}$ \\
\hline S. cerevisiae & $\begin{array}{l}\text { A CRISPR/Cas } 9 \text { toolkit was tested on TXS expression } \\
\text { optimization in yeast. } 10 \text { protein tags and } 5 \text { promoters } \\
\text { of different strengths were tested. Fusion of TXS to }\end{array}$ & Taxadiene titer of 20 mg/L was achieved & $\begin{array}{l}\text { Apel et al., } \\
2017\end{array}$ \\
\hline
\end{tabular}

S. cerevisiae

A. thaliana

Tobacco (Nicotiana sylvestris)

Tomato fruits

Tobacco (Nicotiana benthamiana)

Ginseng (Panax ginseng) roots

Physcomitrella patens (moss)

Alternaria alternata (endophytic fungus) of different strengths were tested. Fusion of TXS to MBP under the strong GAL1 promoter achieved highest titer

TXS-ERG20 fusion protein was constructed with MBP tag for improved solubility, together with promoter strength and growth temperature optimization Chimeric TXS cDNA constitutively expressed in A. thaliana

TSX and T5 $\alpha \mathrm{H}$ were stably expressed in tobacco trichome cells

TXS was stably transformed into a yellow-fruited tomato line which lacks a functional phytoene synthase TXS, truncated $\mathrm{T} 5 \alpha \mathrm{H}$ and cytochrome $\mathrm{P} 450$ reductase were inserted into the chloroplast compartment and precursor pathway was overexpressed

Stable transformation of TXS from Taxus brevifolia into ginseng roots

Stable constitutive expression of TXS using a ubiquitin promoter

Co-overexpression of isopentenyl diphosphate (idi), truncated 3-hydroxy-3-methylglutaryl-CoA reductase (tHMG1) and TXS under different promoter strengths
High taxadiene titer in yeast of $129 \mathrm{mg} / \mathrm{L}$ was achieved in a bioreactor

Taxadiene ( $20 \mathrm{ng} / \mathrm{g}$ DW) in seedlings and leaves, but however observed stunted growth and reduced photosynthetic pigments. Induction with the synthetic glucocorticoid (dexamethasone) improved yields to 600 $\mathrm{ng} / \mathrm{g}$ DW

Taxadiene (no reported yield) was detected while expected taxadiene- $5 \alpha-$ ol was not detected in leaf extracts. Instead, only OCT was detected. Yeast microsomes also produced OCT only

$160 \mathrm{mg} / \mathrm{kg}$ from freeze-dried tomatoes

Taxadiene-56.6 $\mu \mathrm{g} / \mathrm{g}$ FW and Taxadiene- $5 \alpha$-ol was detected for the first time in a heterologous plant platform at $1.3 \mu \mathrm{g} / \mathrm{g}$ fresh weight

TXS-transgenic ginseng accumulated $9.1 \mu \mathrm{g} / \mathrm{g}$ DW. Methyl jasmonate treatment improved yields to $14.6-15.9 \mu \mathrm{g} / \mathrm{g}$ DW

Taxadiene accumulated to $0.05 \% \mathrm{FW}$ of plant tissue. No adverse effects on growth were noted

Detection of $61.9 \mu \mathrm{g} / \mathrm{L}$ taxadiene after 14 days of fermentation
Nowrouzi et al., 2020

Besumbes et al., 2004

Rontein et al., 2008

Kovacs et al., 2007

Li et al., 2019

Cha et al., 2012

Anterola et al., 2009

Bian et al., 2017 


\section{ADVANCES IN METABOLIC ENGINEERING, PROTEIN ENGINEERING AND MECHANISTIC INSIGHTS ON TAXOL RELATED EZYMES}

Synthetic biology tools have been widely applied in advancing Taxol biosynthesis research from gene discovery to pathway designs and construction in heterologous hosts, resulting in successes in detection and accumulation of taxane intermediates. Recent metabolic engineering strategies and achievements in different hosts are summarized in Table 1, together with approaches used in previous years, for comparison. Computational tools are an enabling technology that has also been at the forefront in unraveling mechanistic insights of key enzymes to guide protein engineering strategies for use in metabolic engineering constructs, thus we discuss these advances together in this section.

\section{Quantum Mechanics/Molecular Mechanics (QM/MM) and Computational Modeling of a Catalytically Active TXS to Enable Enzyme Engineering}

The class 1 terpene cyclase taxadiene synthase (TXS) is the first and rate-limiting enzyme of the Taxol biosynthesis pathway. It accepts the acyclic C20 diterpenoid precursor, $(E, E, E)$ geranylgeranyl diphosphate (GGPP) and cyclizes it to the endocyclic diterpene olefin taxa-4(5),11(12)-diene (taxadiene, T) and four other minor products: taxa-4(20), 11(12)-diene (isotaxadiene, T1), verticillia-3(4),7(8),12(13)-triene (V), verticillia- $4(20), 7(8), 11(12)$-triene (V1) and verticillia3(4),7(8),11(12)-triene (V2) (Koepp et al., 1995; Lin et al., 1996; Schrepfer et al., 2016; Li et al., 2019) and also the isomer taxa-3(4),11(12)-diene (Williams et al., 2000b; Li et al., 2019). Though the X-ray crystal structure of TXS was solved almost a decade ago (Köksal et al., 2011), it lacks N-terminal residues and is in an open, catalytically inactive form, which does not provide much clues relevant to the mechanism and intricate architecture of the active form. In addition, the reported structure is bound to the fluorinated substrate, 2-fluoro-geranylgeranyl diphosphate (2-F-GGPP) in a non-productive orientation (Hong and Tantillo, 2011; Schrepfer et al., 2016).

Consequently, labeling and computational tools have been used to get insights on the energetics of proton transfer and carbocation formation in the TXS active site. The generally agreed mechanism follows TXS-catalyzed cleavage of the pyrophosphate moiety (PPi) from GGPP to form charged carbocations followed by subsequent cyclizations and proton transfer, leading to the mixed product profile stated above (Williams et al., 2000a; Köksal et al., 2011). Using QM calculations, an indirect, two-step protein transfer sequence was proposed (Gutta and Tantillo, 2007; Hong and Tantillo, 2011). However, these gas phase calculations assumed a passive role of the TXS protein and placed much emphasis on substrate reactivity. To improve on this prior computational work and identify the role of the deprotonating bases in the TXS active site, more recent work focused on building closed, active models of the protein. Two groups have so far successfully used homology modeling and loop modeling based on the closed structure of bornyl diphosphate synthases (BPPS) as a template to model the missing N-terminal residues and build catalytically active models that can be used in docking the productive substrate, GGPP (Schrepfer et al., 2016; Freud et al., 2017). Such structural model based molecular mechanics calculations have the potential to inform enzyme engineering strategies to generate pathway enzyme variants with improved catalytic efficiency, less product promiscuity or tailored product profile to enable selective attenuation of the carbocation products. For example, closed TXS model construction and molecular mechanics by Schrepfer et al. (2016) led to identification of a conserved amino acid network responsible for an extended hydrogen $(\mathrm{H})$ bonding (water- and amino-acid mediated) involving the PPi and R754, R768, Y835, R580, and N-terminal Y89 in the closed TXS-GGPP complex. Targeted mutagenesis of these five residues lead to loss of activity (Table 2), and the W753 residue was identified as a key deprotonating base for the Cation B (cembren-15-yl cation) that resulted in cembrene $\mathrm{A}$ formation when mutated to a histidine (W753H) or in a double mutant (W753H/C830A) (Table 2; Ansbacher et al., 2018; Schrepfer et al., 2016). In fact, the biotechnological application of these TXS-derived mutants was demonstrated, with $\mathrm{W} 753 \mathrm{H}$ yielding $8 \mathrm{mg} / \mathrm{L}$ cembrene $\mathrm{A}$ and V584M yielding $11 \mathrm{mg} / \mathrm{L}$ verticilla-3,7,12(13)-triene in $30 \mathrm{~L}$ batch fermentations (Schrepfer et al., 2016).

Using the TXS model constructed by Freud et al. (2017), the crucial role of W753 and the analogous Y841 in controlling highly charged carbocations in the hydrophobic TXS active site were highlighted in simulations by Ansbacher et al. (2018). However, recent molecular dynamics (MD) and QM/MM calculations place more emphasis on the role of the reactive carbocations, the retained PPi and active site water molecules in controlling carbocation cascades and product distribution, rather than the TXS residues (Escorcia et al., 2018; van Rijn et al., 2019). The calculations corroborate the critical role of R580 in deprotonation of carbocation C, but suggest this is through water-assisted deprotonation via one or two water bridges, rather than direct interaction with PPi and closure of the active site (as a part of the RXR motif of terpene synthases) as suggested by Freud et al. (2017). Another interesting take from these computational and experimental data sets was the manipulation of the taxadiene and iso-taxadiene product percentage, as this has been shown to be important in determining the selectivity of the subsequent CYP450-catalyzed step as described below. C830S yielded the highest iso-taxadiene without much reduction in overall activity (Table 2), and such a mutant can be leveraged for improving the selectivity of $\mathrm{T} 5 \alpha \mathrm{H}$ as demonstrated by Edgar et al. (2017) (described below).

\section{Strategies Toward Overcoming the $\mathrm{T} 5 \alpha \mathrm{H}$ Bottleneck}

\section{Optimization of Oxygenation Chemistry}

Realizing the magnitude of the bottleneck posed by $\mathrm{T} 5 \alpha \mathrm{H}$, Biggs et al. (2016a) carried out an extensive study to optimize 
TABLE 2 | Mutagenesis of enzymes of the Taxol pathway to manipulate catalytic fitness, activity and product distribution profile.

\begin{tabular}{|c|c|c|c|c|c|c|c|}
\hline Target & Mutation & $\%$ Activity & Taxadiene (T) & Iso-taxadiene (T1) & Verticillenes & Cembrene A & References \\
\hline \multicolumn{8}{|l|}{ TXS } \\
\hline TXS & Wild type & 100 & 93.2 & 4.7 & 2.1 & N.D & Schrepfer et al., 2016 \\
\hline Y89 & Y89A/E/F & Lost activity* & & & & & \\
\hline R580 & R580A/E/H & Lost activity & & & & & \\
\hline $\mathrm{R} 754$ & R754A/E/H & Lost activity & & & & & \\
\hline R768 & R768A/E/H & Lost activity & & & & & \\
\hline Y835 & Y835A/F/W & Lost activity & & & & & \\
\hline \multirow[t]{2}{*}{ V584 } & V584K/L/M & 89-92 & $14-30$ & 0.6 & 70-85.6 & & \\
\hline & V584N/S/P/R & Lost activity & & & & & \\
\hline \multirow[t]{2}{*}{ S587 } & S587D/Y/K/L/G & Lost activity & & & & & \\
\hline & S587A & 21.8 & 8.9 & N.D & 32.2 & 58.9 & \\
\hline Y609 & Y609G & N.A & N.D & N.D & 100 & N.A & Edgar et al., 2017 \\
\hline V610 & V610H/S/F/A & Lost Activity & & & & & Schrepfer et al., 2016 \\
\hline \multirow[t]{2}{*}{$S 713$} & S713T & 97.4 & 92.7 & 5.1 & 2 & N.D & Schrepfer et al., 2016 \\
\hline & $\mathrm{S} 713 \mathrm{~A} / \mathrm{L}$ & Lost activity & & & & & Schrepfer et al., 2016 \\
\hline \multirow[t]{2}{*}{ V714 } & V714A/I & $8.7-10.4$ & 94 & $5.7-5.9$ & N.D & N.D & \\
\hline & V714T/G/P & Lost activity & & & & & \\
\hline G715 & G715A/S & Lost Activity & & & & & \\
\hline \multirow[t]{2}{*}{$S 713$} & S713T & 97.4 & N.D & N.D & N.D & 100 & \\
\hline & S713A/L & Lost activity & & & & & \\
\hline \multirow[t]{3}{*}{ W753 } & W753H & 51.3 & N.D & N.D & N.D & 100 & $\begin{array}{l}\text { Schrepfer et al., 2016; } \\
\text { Ansbacher et al., } 2018\end{array}$ \\
\hline & W753H/C830A & 48.5 & N.D & N.D & N.D & 100 & Schrepfer et al., 2016 \\
\hline & W753A/C/E/LN & Lost activity & & & & & \\
\hline \multirow[t]{2}{*}{ C830 } & C830A & 88.5 & 93.1 & 4.8 & 2.1 & N.D & \\
\hline & C830S & 92.4 & 79.3 & 7.3 & 13.4 & N.D & \\
\hline F834 & F834A/G & 25.6-28.3 & $38-87$ & $6.1-6.5$ & & & \\
\hline \multirow[t]{2}{*}{ Y835 } & Y835F & 3.5 & 100 & N.D & N.D & N.D & \\
\hline & Y835AW & Lost activity & & & & & \\
\hline \multirow[t]{2}{*}{ Y841 } & Y841F & 41.3 & N.D & N.D & 43.6 & 56.4 & \\
\hline & Y841A/T & Lost activity & & & & & \\
\hline Y6889 & Y688L & 2.4-fold incre & in $\mathbf{T 1}$, and corre & nding increase in T-5 $\alpha$-ol & & & Edgar et al., 2017 \\
\hline \multicolumn{8}{|l|}{ T5 $\alpha \mathbf{H}$} \\
\hline T380 & T380S & \multicolumn{5}{|c|}{ Produced a dihydroxylated product-5(12)-oxa-3(11)-cyclo-taxan-10-ol } & Edgar et al., 2017 \\
\hline K131 & K131R & \multicolumn{5}{|c|}{ Improved turnover but lost selectivity compared to wild type } & Yadav, 2014 \\
\hline V374 & V374L & \multicolumn{5}{|c|}{ Improved selectivity at the expense of turnover } & \\
\hline S302 & S302A & \multicolumn{5}{|c|}{ Lost activity and no change in fold-change } & \\
\hline \multicolumn{8}{|l|}{ DBAT } \\
\hline G38 & G38R & \multicolumn{5}{|c|}{ 2.15-fold increase in baccatin III } & Li et al., 2017 \\
\hline \multirow[t]{2}{*}{$\mathrm{H} 162$} & H162A & \multicolumn{5}{|l|}{ Lost activity } & Li et al., 2017 \\
\hline & H162A/R63H & \multicolumn{5}{|c|}{ 3-fold increase in catalytic activity compared to wild type } & You et al., 2018 \\
\hline \multirow[t]{2}{*}{ R363 } & R363A & Lost activity & & & & & Li et al., 2017 \\
\hline & $\mathrm{R} 363 \mathrm{H}$ & 26-fold increa & in catalytic activit & mpared to wild type & & & You et al., 2018 \\
\hline G361 & G361A & Lost activity & & & & & Li et al., 2017 \\
\hline 1164 & I164A & Lost activity & & & & & Li et al., 2017 \\
\hline D166 & D166H & 15-fold increa & in catalytic activit & mpared to wild type & & & You et al., 2018 \\
\hline & D166H/R363H & 60-fold increa & in catalytic activit & mpared to wild type & & & You et al., 2018 \\
\hline 143/D390 & |43S/D380R & 3.3-fold incre & in catalytic efficie & using vinyl acetate and & old using acety & & Lin et al., 2018 \\
\hline
\end{tabular}

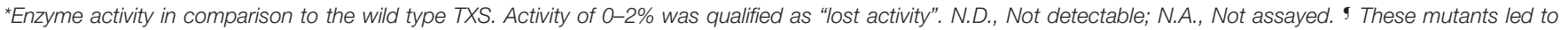
corresponding increases in taxadiene-5 $\alpha$-ol after introduction of T5 $\alpha \mathrm{H}$-CPR.

P450 chemistry in E. coli as a proof of concept and achieved a fivefold increase in oxygenated taxanes, reaching the highest oxygenated diterpene titer to date $(\sim 570 \mathrm{mg} / \mathrm{L})$. The work built from the MMME breakthrough (Ajikumar et al., 2010) and aimed to optimize downstream P450 chemistry through chromosomal integration of the upstream pathways and use 
of different strategies to optimize $\mathrm{T} 5 \alpha \mathrm{H}$ and cytochrome $\mathrm{P} 450$ reductase (CPR) partner interactions. A protein interdependency of the oxidative module and the upstream modules was uncovered through targeted proteomics, and was determined as a key obstacle of $\mathrm{T} 5 \alpha \mathrm{H}$ expression and to be responsible for reduction of upstream metabolites on introduction of $\mathrm{T} 5 \alpha \mathrm{H}$. Strategies used to uncouple this interdependency and optimize the pathway proteins were varying promoter strength, $\mathrm{N}$-terminal modifications, gene copy number optimization and optimization of CPR interactions (Figure 2A). Construction of the $\mathrm{T} 5 \alpha \mathrm{H}$-CPR module as an operon resulted in higher titers compared to a linked, chimera construct; and a weaker Trc promoter demonstrated overall higher yields compared to a stronger T7 promoter. These results suggested the need for a lowered CPR expression as evidenced by the benefits of an operon construction and Trc promoter. To address the solubility issue that is common with P450 enzymes, truncation of the hydrophobic, membrane-targeting $\mathrm{N}$-termini of both $\mathrm{T} 5 \alpha \mathrm{H}$ and CPR was undertaken, and three leader peptides of different solubilities (8RP, MA, and 2B1) were attached for N-terminal modifications. Despite the significant improvement in solubility of the expressed respective proteins that was noted, there were no benefits of these modifications on $\mathrm{T} 5 \alpha \mathrm{H}$ performance, in fact, increased hydrophilicity (2B1-T5 $\alpha \mathrm{H} / 2 \mathrm{~B} 1-\mathrm{CPR})$ resulted in accumulation of taxadiene that was not converted to oxidized taxanes. Ultimately, this work developed a strain with a chromosomally integrated MMME module and T5aH-CPR in an operon construct in a low copy plasmid under a weak Trc promoter as the most optimal that achieved $\sim 570 \mathrm{mg} / \mathrm{L}$ oxygenated taxanes in a benchtop bioreactor.

As demonstrated by Biggs et al. (2016a), optimizing promoter strength to strike a balanced expression of pathway enzymes or achieving dynamic expression is a very powerful tool in metabolic engineering and synthetic biology. In the context of the Taxol pathway, this tool was recently exploited to finely tune expression of TXS and GGPPS using bidirectional promoters (BDPs) in the yeast Pichia pastoris (Vogl et al., 2018). BDPs allow not only differential expression of genes utilizing differences in promoter strength, but can be used to explore constitutive and inducible promoters, and for timing where one gene needs to be expressed after another (Figure 2B). When GGPPS was expressed under a constitutive promoter, no taxadiene was detected, but when GGPPS was under a depressed promoter and TXS under a different promoter, taxadiene titers increased by nearly 60 -fold (Vogl et al., 2018). Though this strategy was not extended to $\mathrm{T} 5 \alpha \mathrm{H}$, the same study already provided a promising example with a human P450 and its CPR partner that improved by fivefold under an optimal BDP. Another example of the versatility of manipulating promoters for dynamic pathway expression to overcome the $\mathrm{T} 5 \alpha \mathrm{H}$ bottleneck is a recent report using riboregulated switchable feedback promoters (rSFPs) (Glasscock et al., 2019). These novel rSFPs are created through using a natural, stress-response promoter in conjunction with a target sequence that is inserted between the promoter and the gene. A separate trans-acting regulator, called small transcription activating RNA (STAR) is introduced in a second plasmid to bind and activate the rSFP, creating a gated ON/OFF switch for the downstream gene (Figure 2B). Working with the best optimized strain from Biggs et al. (2016a), this rSFP tool was used to screen membrane envelope stress-response promoter library with the goal to create a promoter that is responsive to the stress caused by introduction of T $5 \alpha \mathrm{H} / \mathrm{CPR}$ to the upper pathways. Optimization of the timing and expression magnitude of T5 $\alpha \mathrm{H} / \mathrm{CPR}$ with rSFP in this way resulted in a notable improvement of 2.4-fold $(25.4 \mathrm{mg} / \mathrm{L})$ in oxygenated taxanes and 3.6 -fold $(39.0 \mathrm{mg} / \mathrm{L})$ increase in total taxanes (Glasscock et al., 2019).

CRSIPR/Cas9 technology is a fast and precise enabling tool that is increasingly being used in synthetic biology applications. This technology was applied to build a cloning-free screening toolkit for promoter strength and solubility tag optimization in S. cerevisiae (Apel et al., 2017) to enable quick exploration of different constructs. As a proof of concept, the toolkit was applied to build an expression context library for TXS to explore localization tags, solubility tags and promoter strength. The fast toolkit identified a solubility problem with TXS in yeast as the major cause of poor catalysis, and identified the best optimized construction of TXS with MBP solubility tag and a strong GAL1 promoter that increased titers 25 -fold compared to an optimized strain.

\section{$\mathrm{T} 5 \alpha \mathrm{H}$ Protein Engineering}

While all the above tools are promising for optimizing $\mathrm{T} 5 \alpha \mathrm{H}$ expression, it is important to note that the improvements are in titers of "oxygenated taxanes", a term describing a mixture of different mono- and doubly oxygenated taxanes monitored at $\mathrm{m} / \mathrm{z} 288$ and $\mathrm{m} / \mathrm{z} 304$ in the GC-MS chromatograms. The only product of $\mathrm{T} 5 \alpha \mathrm{H}$ that has been shown to lead to Taxol is $\mathrm{T}-5 \alpha-\mathrm{ol}$, thus, though increases in total oxygenated taxanes are promising, it is highly desired to address product promiscuity of the enzyme, and devise ways to improve only the desired product (i.e., T-5 $\alpha$-ol). Protein engineering is an effective tool that has already been harnessed to address the $\mathrm{T} 5 \mathrm{\alpha H}$ bottleneck, and to improve other enzymes of the Taxol pathway (Figure 3). Notwithstanding major advancements in directed evolution as a subfield that recently won a Nobel price, the major challenges with leveraging this tool in engineering $\mathrm{T} 5 \alpha \mathrm{H}$ and other $\mathrm{P} 450 \mathrm{~s}$ of the Taxol pathway is the dearth of mechanistic knowledge of catalysis and the lack of high throughput screening assays to quickly screen the large number of generated mutants. Assuming that the experimentally observed product promiscuity of $\mathrm{T} 5 \alpha \mathrm{H}$ was due to competing regiospecific proton abstraction by the oxyferryl species of the P450 enzyme on taxadiene as proposed previously (Hefner et al., 1996; Jennewein et al., 2004), a computational method was developed to guide mutagenesis and improve catalytic efficiency and selectivity (Yadav, 2014). A total of 53 mutants were designed targeting amino acids residues around the active site of the enzyme, basing on an energyminimized homology model of $\mathrm{T} 5 \alpha \mathrm{H}$ that was developed using six P450 structures as template. Assessment of the mutant library identified six variants ( 5 single and 1 triple mutant) that improved both in turnover and T-5 $\alpha$-ol selectivity, though the identities of the mutants were not clearly stated and the mechanistic basis of the improvements was not discussed. Three mutants from the study were however used to infer mechanistic basis on the 


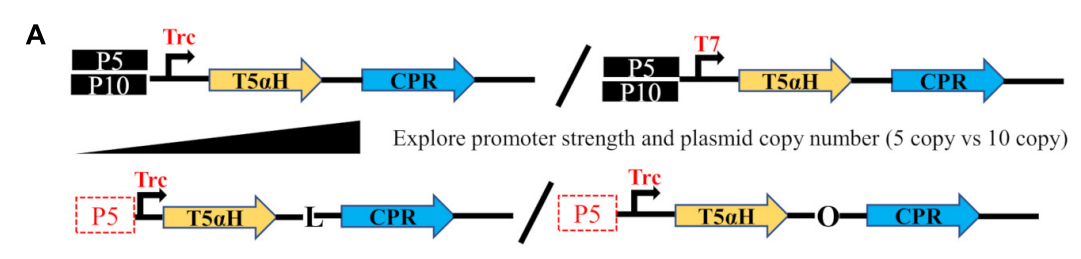

Optimize Construct design. Linked Chimera (L) or Unlinked Operon (O)

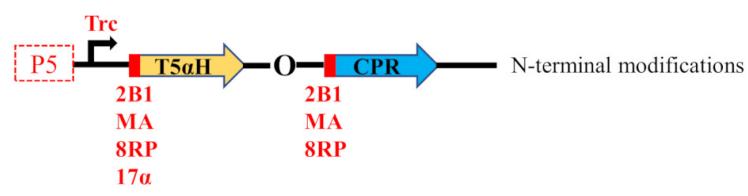

B
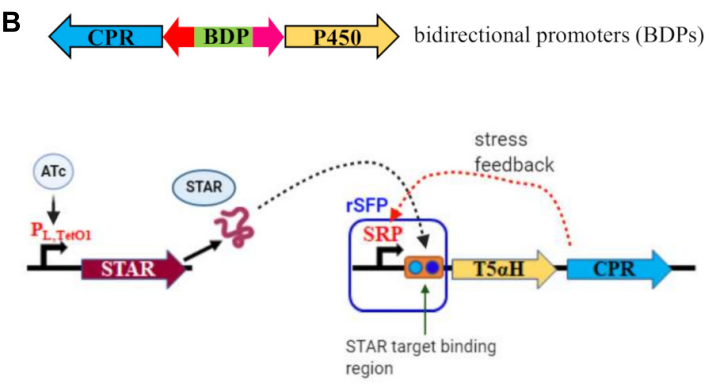

Riboregulated Switchable Feedback promoters (rSFPs)

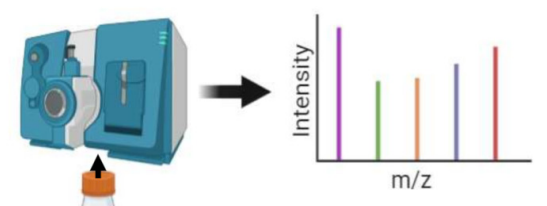

Optimize fermentation Hungate fermentation; Media, Temperature optimization

FIGURE 2 | Tools and strategies used to overcome the T5 $\alpha \mathrm{H}$ bottleneck. (A) Optimization of the P450 module in a previously optimized E. coli strain with chromosomally integrated MEP and TG modules was achieved using several approaches (see Biggs et al., 2016a). Top panel-A high copy number plasmid (P10) was compared to a low copy number (P5), and expression strength was explored using a strong T7 promoter and a weak (Trc) promoter; Middle panel-Using a low copy P5 plasmid and weak Trc promoter, interactions of the P450 and its reductase partner CPR were explored using a linked chimera construct (L) or an unlinked operon design (O); Lower panel-N-terminal modifications were tested on truncated versions of T5 $\alpha \mathrm{H}$ and $\mathrm{CPR}$ to enhance solubility using three leader peptides-2B1, MA an 8RP; 17 $\alpha$ was also used in another study (Rouck et al., 2017). Right panel-Further optimizations including targeted proteomics and optimization of media and fermentation conditions led to highest titers of oxygenated taxanes. (B) Targeting promoters for dynamic regulation of T5 $\alpha \mathrm{H}$ catalysis. Top-Bidirectional promoters (BDPs) that differ in inducibility and strength can be used for fine-tuning and timing of expression of proteins in the Taxol pathway. Vogl et al. (2018) tested this concept and achieved a 50x-improvement in taxadiene titers. Lower-Glasscock et al. (2019) introduced riboregulated Switchable feedback promoter (rSFP) that uses a natural stress-response promoter (SRP) in combination with a second plasmid containing a small transcription activating RNA (STAR) that can be induced by an inducer like anhydrotetracycline (ATC) to create an external ON/OFF gate that achieved a 2.4-fold increase in oxygenated taxanes compared to Biggs et al. (2016a). (C) Compartmentalized engineering in plant tissue (N. benthamiana) targeting chloroplasts (Li et al., 2019) and cytosol (De La Peña and Sattely, 2020) was conducted. Plastid-chloroplastic targeting (blue arrows) resulted in production of T-5 $\alpha$-ol for the first time, while cytosolic targeting (red arrows) resulted in 10-fold increase in taxadiene. Purple arrows-upregulation of HMGR without cytosol-targeted tcTXS-tcGGPPS led to 80x increase in an unidentified compound that co-eluted with taxadiene. Black arrows-introduction of DXS and TXS-GGPPS without chloroplastic targeted chIT5 $\alpha \mathrm{H}$-chICPR results in detection of OCT only. Red dotted arrow, cytosolic engineering of taxadiene with further introduction of T5 $\alpha \mathrm{H}-\mathrm{CPR}$ has not yet been attempted.

observed changes; S302A, K131R, and V374L (Table 2). Product promiscuity was slightly improved in the identified mutants, but $\mathrm{T}-5 \alpha$-ol remained a minor product while OCT and iso-OCT dominated the product profile.

A different $\mathrm{T} 5 \alpha \mathrm{H}$ mechanism involving an epoxide intermediate, as opposed to an exclusive radical intermediate, was suggested by the Stephanopoulos group (Edgar et al., 2016). Under this proposal, the two main products of TXS ( $\mathbf{T}$ and $\mathbf{T 1}$ ) undergo catalysis through different transition states en-route to T-5 $\alpha$-ol; T1 follows the radical-rebound mechanism (abstraction at the $\mathrm{C} 20$ - position), while $\mathbf{T}$ follows epoxidation route to an unstable epoxide intermediate that decomposes non-selectively to several products like OCT, iso-OCT, and T-5 $\alpha$-ol (Figure 3A). The proposal was supported by several lines of evidence, and it was experimentally determined that incubating taxadiene with TXS leads to several products, but incubating with iso-taxadiene produced a single peak of T-5 $\alpha-\mathrm{H}$. Another independent chemical synthesis study provided direct evidence that indeed $\mathbf{T}$ can be epoxidized in a regio- and diastereoselective manner to yield the intermediate taxadiene-4(5)-epoxide that can be further rearranged into T-5 $\alpha$-ol, OCT, and iso-OCT (Barton et al., 2016). These observations are significant, and support that $\mathrm{T} 5 \alpha \mathrm{H}$ catalysis is substrate-driven, and that the broad product profile is a result of non-selective epoxide degradation rather than $\mathrm{T} 5 \alpha \mathrm{H}$ non-selectivity as previously assumed. Based on this alternative mechanistic proposal, three targets can be manipulated for enhancing selectivity of $\mathrm{T} 5 \alpha \mathrm{H}$ hydroxylation; (i) manipulating TXS selectivity to enhance T1 in the product profile, (ii) engineering $\mathrm{T} 5 \alpha \mathrm{H}$ to improve turnover and (iii) searching for an epoxidase enzyme to improve selectivity of the hypothesized epoxidase intermediate (Figure 3B). All three approaches were conducted and TXS engineering to enhance T1 titers resulted in variants that displayed 2.4-fold improvement in T1 leading to a 2.4-fold improvement in T-5 $\alpha$-ol titers in E. coli 

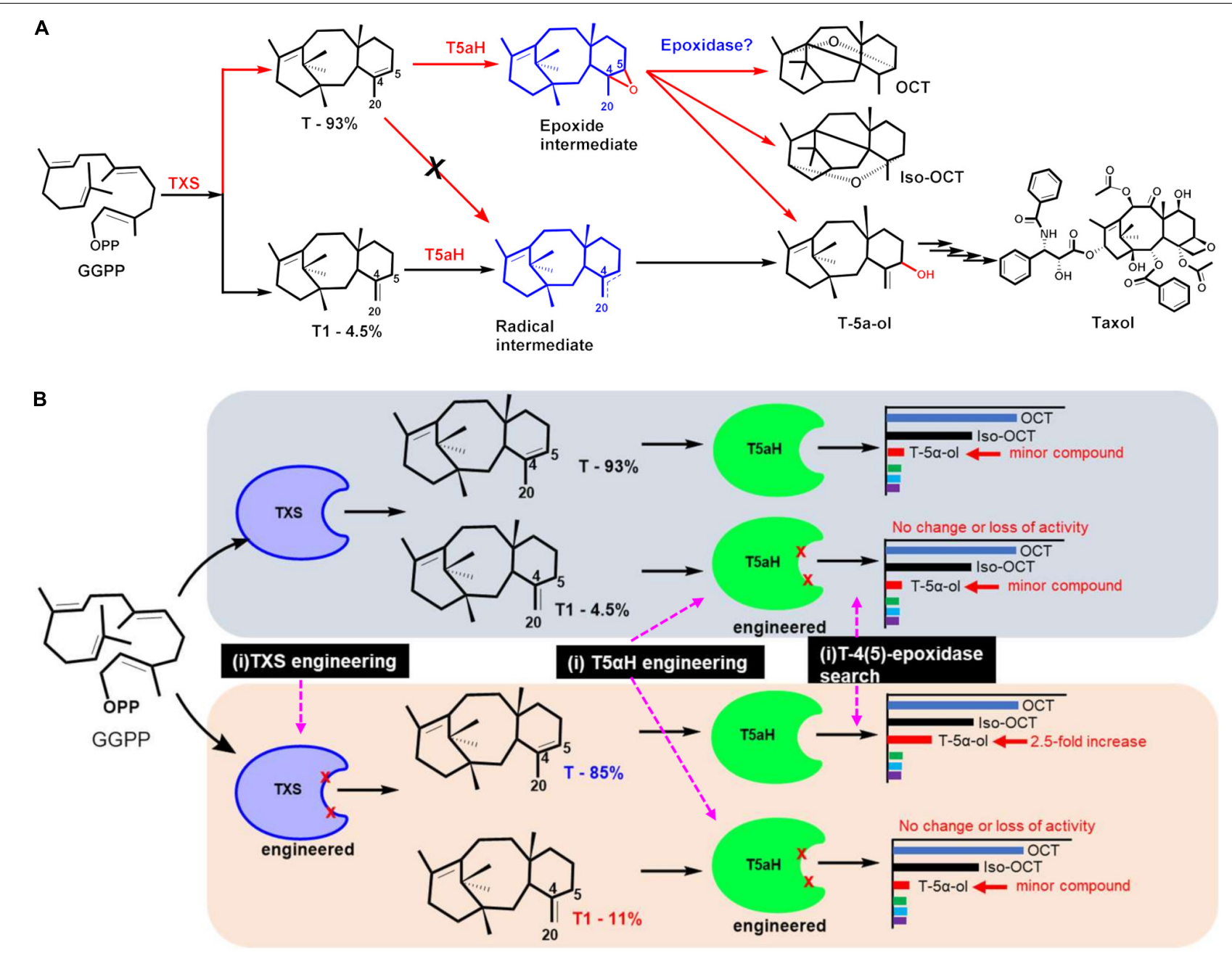

FIGURE 3 | Improving T5 $\alpha \mathrm{H}$ catalysis through mechanism-informed protein engineering strategies (based on Edgar et al., 2016, 2017). (A) A novel mechanism of $\mathrm{T} 5 \alpha \mathrm{H}$ catalysis was proposed, via an unstable epoxidase intermediate. Under this proposal, the mechanism of T5 $\alpha \mathrm{H}$ catalysis is substrate controlled. Taxadiene (T) undergoes catalysis through the proposed epoxide (red arrows), leading to several products like OCT, T-5 $\alpha$-ol and iso-OCT, while iso-taxadiene (T1) follows the radical rebound mechanism (black arrows) that exclusively leads to the desired T-5 $\alpha$-ol product and ultimately to Taxol. (B) Exploring engineering targets to improve $\mathrm{T} 5 \alpha \mathrm{H}$ catalytic specificity toward T-5 $\alpha$-ol. Three strategies: (i) TXS engineering to improve iso-taxadiene yield, (ii) T5 $\alpha \mathrm{H}$ engineering to improve catalytic efficiency and specificity and (iii) mining for an epoxide that could convert the epoxidase to T-5 $\alpha$-ol. Engineered TXS with improved T1 percentage improved T-5 $\alpha$-ol yield 2.5 -fold.

after reconstituting T5 $\alpha \mathrm{H}-\mathrm{CPR}$ (Edgar et al., 2017). A total of 14 residues consisting of polar residues near the TXS active site, residues closer to $\mathrm{PPi}$, and two residues in the $\mathrm{N}$-terminus that caps the active site were investigated by saturation mutagenesis, and the most successful mutant was Y688L. In fact, in addition to the critical PPi assisted abstraction, docking simulations also identified Y688 as a critical residue for abstraction of the hydrogen on C-5 position. Mutation of $\mathrm{N}$-terminal residues led to a loss of activity, a result that was in agreement with Schrepfer et al. (2016). Mutagenesis of the P450 enzyme and mining of a novel T-4(5)-epoxidase were not successful, but with the increasing amount of Taxus transcriptome datasets and the substrate synthesis methodology reported by Barton and colleagues, further querying, in vitro screening and activityguided fractionation are promising methods in searching for this enzyme. In addition to T-5 $\alpha$-ol-enhancing mutations, other TXS mutants were identified that yield verticillines (Q609G), or other unidentified compounds, most likely cembrene A (Table 2).

\section{Semi-Rational Designing of DBAT}

Besides the first two enzymes of the Taxol pathway, other downstream enzymes have also been targeted for engineering enhanced catalysis. For example, DBAT was engineered with the aid of a computational semi-rational strategy, leading to a double mutant (I43S/D390R) that not only improved catalytic efficiency but could more efficiently utilize vinyl acetate, a cheaper alternative acyl donor compared to acetyl CoA (Lin et al., 2018). Compared to the wild type DBAT, the double mutant improved catalytic efficiency by 3.3-fold when using vinyl acetate, and 2.99-fold when using acetyl CoA (Table 2). Employing a similar computationally guided semi-rational design, Li et al. (2017) employed structure 
modeling, molecular docking, alanine scanning and saturation mutagenesis to engineer DBAT for acetylation of the C10 position of 10-deacetyltaxol (DT) with the aim to utilize the C7-gylcosylated Taxol analog (7- $\beta$-xylosyl-10-deacetyltaxol) for Taxol biosynthesis. The double mutant engineered in the study (G38R/F301V) demonstrated 6-fold improvement in catalytic efficiency (acetylation of DT to Taxol) compared to wild type DBAT, and in addition, a mutant (G38R) was identified with 2.15-fold improved catalytic efficiency in converting the native substate (10-deacetyl baccatin) to baccatin III. Molecular docking also revealed the critical catalytic role of His162 in DBAT catalysis, and alanine scanning identified 4 residues that led to a complete loss of activity when mutated to alanine (H162A, R363A, G361A, and I164A). Two of these residues (H162 and R363) and an additional active site residue (D166) were further investigated by another group by a similar computational strategy supported by site directed mutagenesis (You et al., 2018). Postulating the benefits of histidine residues in the DBAT catalytic pocket, these residues were mutated to histidine, leading to $\mathrm{D} 166 \mathrm{H}, \mathrm{R} 363 \mathrm{H}, \mathrm{H} 162 \mathrm{~A} / \mathrm{R} 363 \mathrm{H}$, and $\mathrm{D} 166 \mathrm{H} / \mathrm{R} 363 \mathrm{H}$ that demonstrated superior catalytic activities (15-, 26-, 3-, and 60times improvements compared to wild type DBAT, respectively) (Table 2).

Computational tools are increasingly becoming useful in gaining mechanistic insights on the catalysis cycles of Taxol pathway enzymes. The above examples highlight how versatile and powerful the tool was leveraged for several proteins. Cytochrome $\mathrm{P} 450 \mathrm{~s}$ are very sensitive to mutations, thus computational and phylogenetically guided mutagenesis studies of $\mathrm{T} 5 \alpha \mathrm{H}$ have so far not yet identified significantly improved mutants for solving this bottleneck. Nevertheless, given the lack of a X-ray crystal structure of $\mathrm{T} 5 \alpha \mathrm{H}$ or any CYP450 of the Taxol pathway, homology modeling and molecular docking have thus far provided three models (Edgar et al., 2017; Rouck et al., 2017; Yadav, 2014) that can guide semi-rational design strategies. Several residues were identified in the resulting docking conformations that are potentially involved in stabilizing the hydrophobic taxadiene, reaction intermediates and the heme that could shed light on the mechanism of catalysis.

\section{Metabolic Engineering in Plant Hosts}

Plant hosts are expected to offer a more favorable environment for the challenging functional expression of plant CYP540 that currently frustrates engineering of the pathway in microbial hosts. Taxol pathway genes are located in different organelles in the plant cell (cytosol, endoplasmic reticulum membranes, and chloroplasts) but the nature of the exchange of intermediates among these different locations is not known. We considered inter-organellar transport of taxane intermediates to be the major barrier blocking access of endoplasmic reticulum-localized CYP450s to their diterpenoid substrate produced in the plastid in plant cells and used a compartmentalized engineering strategy that led to production of $\mathrm{T}-5 \alpha$-ol in a heterologous plant host for the first time (Li et al., 2019; Figure 2C). A very recent report similarly targeted TXS and GGPPS in the cytosol and overexpressed the mevalonate pathway rate limiting enzyme 3-hydroxy-3-methylglutaryl-CoA reductase
(HMGR) and observed a 10-fold improvement in taxadiene yields in N. benthamiana leaves (De La Peña and Sattely, 2020). Given the robustness of the mevalonate pathway compared to the MEP pathway, cytosolic targeting could potentially open new avenues for engineering taxanes in plant cells. It remains to be tested if this cytosolic compartmentalization strategy could be leveraged for engineering production of oxygenated taxanes.

\section{NOVEL CANDIDATE GENES AND INSIGHTS FROM RECENT TRANSCRIPTOME DATA}

Advances in sequencing technology in the last decade opened avenues for gene discovery and pathway elucidation of Taxol biosynthesis. Almost all novel genes identified in the early days were discovered through leveraging homology-based cloning, random sequencing of cDNA libraries from MeJAelicited Taxus cell cultures, differential display of mRNA-reverse transcription-PCR, screening of EST libraries and use of available substrates and surrogate substrates (see reviews by Walker and Croteau, 2001; Kaspera et al., 2006). The advent of high throughput RNA sequencing technologies presented a very powerful tool that enabled transcriptome and genome sequencing, generating a huge amount of data that often is challenging to analyze and infer meaningful biological relevance. To date, powerful sequencing technologies using next-generation sequencing (NGS) and third-generation sequencing (TGS) platforms have been applied in transcriptomic studies of Taxus tissues and cell suspension cultures. Recent years have witnessed an increased interest in sequencing Taxol-related transcriptomes, revealing unprecedented insights into regulatory mechanisms of the pathway, unraveling mechanistic links to plant hormone signal transduction pathways and providing several lead candidates for the missing pathway genes-with some that have already been confirmed functional.

A transcriptome study was conducted with MeJAelicited T. baccata suspension cells using high throughput complementary DNA-amplified fragment length polymorphism (cDNA-AFLP) that provided a total of 15 candidate transcripts identified as potential lead candidate genes encoding the six remaining enzymes (PCL, T1 $\beta \mathrm{H}, \mathrm{T} 9 \mathrm{O}, \mathrm{C} 4-\mathrm{C} 20$ epoxidase, $\mathrm{T} 2^{\prime} \alpha \mathrm{H}$, and oxomutase) of the Taxol pathway. Functional characterization of these candidates led to the isolation of PCL (Ramírez-Estrada et al., 2016). A combined transcriptomic assembly of Taxus chinensis cultured cells and in silico mining of publicly available transcriptome data sets covered a comprehensive list of CYP450 genes, creating a valuable resource for searching the missing enzymes and for finding alternative $\mathrm{P} 450$ s for bottleneck enzymes like $\mathrm{T} 5 \alpha \mathrm{H}$ (Liao et al., 2017). A total of 118 full length and 175 partial length T. chinensis P450s were identified, including the five known P450s of the pathway (CYP725A1-T10 $\beta \mathrm{H} ; \quad$ CYP725A2-T13 $\alpha \mathrm{H} ; \quad$ CYP725A4$\mathrm{T} 5 \alpha \mathrm{H}, \quad \mathrm{CYP} 725 \mathrm{~A} 5-\mathrm{T} 7 \beta \mathrm{H}, \quad \mathrm{CYP} 725 \mathrm{~A} 6-\mathrm{T} 2 \alpha \mathrm{H})$ and six novel CYP725A subfamily genes (CYP725A9, CYP725A11, 
CYP725A16, CYP725A20, CYP725A22, CYP725A23). The same three sets of publicly available transcriptome datasets from T. chinensis cultured cells were mined for WRKY transcription factors leading to identification of 61 transcripts of TcWRKY of which six selected genes were all upregulated by MeJA (Zhang et al., 2018a).

Other recent Taxol-related transcriptomes covered a taxolproducing endophytic fungi Cladosporium cladosporioides MD2 (Miao et al., 2018), profiling of time-series reprogramming of Taxus $x$ media genes following MeJA treatment (Mao et al., 2018), comparison of wild type T. yunnanensis with a high Taxol and 10-DAB-yielding new cultivar ( $\mathrm{He}$ et al., 2018), comparative transcriptomes of T. media, T. marei, and T. cuspidata that differ in Taxol content (Zhou et al., 2019) and Iso-Seq of T. cuspidata tissues (Kuang et al., 2019). The Iso-Seq transcriptome identified nine CYP450s and seven acyl transferases (ACTs) as possible lead candidates for Taxol biosynthesis. The utility of transcriptome data sets in novel gene discovery, unraveling of biosynthetic and regulatory mechanisms was demonstrated in numerous examples discussed above. An in-depth computational and experimental analysis of the cDNA-AFLP dataset previously analyzed by Ramírez-Estrada et al. (2016) was recently conducted by the same group, leading to identification of transcript TB506 as a putative Taxane $2^{\prime}$ a hydroxylase $\left(\mathrm{T} 2^{\prime} \alpha \mathrm{H}\right.$ ) (Sanchez-Muñoz et al., 2020). Molecular docking was conducted to confirm binding of such a huge substrate as $3^{\prime} \mathrm{N}$-dehydroxydebenzoyltaxol and possible conformations were achieved. Functional expression and characterization of $\mathrm{T}^{\prime} \alpha \mathrm{H}$ activity was confirmed in Pisum sativum protoplasts, opening a biotechnological route to Taxol from its available intermediates $10-\mathrm{DAB}$ and BIII.

In another recent study relevant to biotechnological production of Taxol, a library of 17 acyl CoA transferases (ACTs) was mined from three publicly available RNA-Seq data sets (from MeJA-elicited T. media suspension cell cultures) and screened for activation of different organic acids for $\mathrm{N}$-substitution of 3-phenylisoserine side chain of taxoids (Srividya et al., 2020). In addition to identification of a candidate ACT with high specificity for generating CoA ester of benzoic acid (leading to Taxol formation) the study identified and functionally characterized several ACTs responsible for inserting different groups on this position, leading to several observed taxoids like Taxol B (insertion of a hexanoic acid), Taxol C (tiglic acid) and Taxol D (butyric acid). An ACT clone with 99\% identity to the one described above (Ramírez-Estrada et al., 2016) was isolated, but activity screening of the clone, and all other candidates by Srividya et al. (2020) did not yield a positive hit.

Biochemical assays have been used to confirm several regulatory mechanisms inferred from deep sequencing studies. Using a GUS reporter assay with promoters of seven pathway genes from Taxus cuspidata cells, three basic helix-loophelix (bHLH) transcription factors (TcMYC1, TcMYC2, and TcMYC4) were identified as negative regulators of MeJA-induced Taxol biosynthesis through their interaction with E-boxes in the promoters of Taxol pathway genes (Lenka et al., 2015). A more recent study, however, used GUS reporter assays in combination with yeast-one-hybrid, yeast-two-hybrid and in vitro assays and revealed TcMYC2a as a positive regulator of TXS in JA signaling (Zhang et al., 2018b). It relays its positive signal through binding JAZ proteins, and interacting with promoters of ERF15, ERF12, and TXS through the T/G-box, G-box, and E-box in their promoters.

\section{PERSPECTIVES AND CONCLUDING REMARKS}

Most genes of the Taxol pathway were isolated and their encoded proteins were functionally characterized is different systems. However, successes in functional expression of individual genes were not replicated when sequential genes were constructed into a pathway to synthesize intermediates. The most successful heterologous production of a taxane intermediate was $1 \mathrm{~g} / \mathrm{L}$ achieved 10 years ago through an MMME approach, but introduction of $\mathrm{T} 5 \alpha \mathrm{H}$ that catalyzes the second step to the strain led to a dramatic loss of both optimality and titers. The past 5 years witnessed a significant increase in application of synthetic biology tools together with the emerging enabling technologies for gene assemblies in enzyme discovery and metabolic engineering of taxane intermediates. Several synthetic biology tools have been leveraged to optimize $\mathrm{T} 5 \alpha \mathrm{H}$ expression and activity, including truncations, promoter optimization, CPR optimization and compartmentalized engineering in plant organelles and use of riboregulated switchable feedback promoters (rSFPs). Computational and experimental approaches were used to improve our understanding of the catalytic mechanism of TXS and T5 $\alpha \mathrm{H}$, shedding more light on the transition states governing the observed product profile. Models of the closed TXS and those of T5 $\alpha \mathrm{H}$ and DBAT were also built that provided intricate details of the active site architecture to guide semi-rational protein engineering strategies to improve catalytic activity and alter product profile.

As highlighted throughout this review, most strategies in the past 5 years were focused on $\mathrm{T} 5 \alpha \mathrm{H}$. This is because this enzyme catalyzes the most important bottleneck of the pathway. With a taxadiene conversion rate of less than $10 \%$, and a product profile comprising several monooxygenated and few dioxygenated taxanes, it's not surprising that strategies that aimed to increase supply of precursors, or those aiming to improve catalytic activity did not achieve much improvements since this is a major branching point of the pathway that splits flux into several off-target taxanes. The successes recorded through optimized expression (operon constructs, use of low strength promoters and low copy plasmids), a clever approach to couple expression of the protein to cell envelope stress through rSFPs, compartmentalized engineering in chloroplasts of plant cells and engineering of TXS to favor iso-taxadiene product that proved to exclusively lead to T-5 $\alpha$-ol are approaches that we expect to be further developed in the near future, utilizing such enabling tools as the CRISPR/Cas9 toolkit developed for S. cerevisiae. Nicotiana benthamiana, a high biomass plant with available technologies for DNA manipulation and agrobacterium-mediated transient expression systems is very promising as a chassis for heterologous 
expression of the Taxol pathway and is increasingly being favored for production of many other terpenoids. The Taxol pathway that comprises nine CYP450s that trigger membrane envelope stress on their expression in host cells as demonstrated with $\mathrm{T} 5 \alpha \mathrm{H}$, is a very good candidate for expression in N. benthamiana.

Advances is high throughput sequencing technologies have enabled generation of several Taxol-related transcriptomes, and recent mining of these publicly available resources have led to isolation of two missing genes, PCL and $\mathrm{T} 2{ }^{\prime} \alpha \mathrm{H}$, though wide testing of PCL in different heterologous hosts is yet to be conclusive. Dozens of lead candidate genes for the missing steps were identified through mining transcriptomes, and with more screening platforms being established, we anticipate full elucidation of the pathway in the near future. Furthermore, we anticipate gas phase QM/MM calculations and experimental methods to reveal the mechanism of catalysis of $\mathrm{T} 5 \alpha \mathrm{H}$ that will guide protein engineering to overcome the bottleneck, as was done for TXS and DBAT. As sequencing technology advances in the coming years, we also expect a high-resolution genome of Taxus species to be assembled that will complement transcriptome data sets and accelerate gene discovery of the remaining CYP450s, PCL, and an epoxidase. Synthetic biology tools are expected to play an increasingly important role in enzyme discovery, construction and optimization of the pathway in different chassis and silencing of competing pathways.

\section{REFERENCES}

Abdallah, I. I., Pramastya, H., Van Merkerk, R., and Sukrasno Quax, W. J. (2019). Metabolic engineering of Bacillus subtilis toward taxadiene biosynthesis as the first committed step for taxol production. Front. Microbiol. 10:218. doi: 10.3389/ fmicb.2019.00218

Ajikumar, P. K., Xiao, W. H., Tyo, K. E. J., Wang, Y., Simeon, F., Leonard, E., et al. (2010). Isoprenoid pathway optimization for Taxol precursor overproduction in Escherichia coli. Science 330, 70-74. doi: 10.1126/science.1191652

Ansbacher, T., Freud, Y., and Major, D. T. (2018). Slow-starter enzymes: role of active-site architecture in the catalytic control of the biosynthesis of taxadiene by Taxadiene synthase. Biochemistry 57, 3773-3779. doi: 10.1021/acs.biochem. 8 b00452

Anterola, A., Shanle, E., Perroud, P. F., and Quatrano, R. (2009). Production of taxa-4(5),11(12)-diene by transgenic Physcomitrella patens. Transgen. Res. 18, 655-660. doi: 10.1007/s11248-009-9252-5

Apel, A. R., Espaux, L., Wehrs, M., Sachs, D., Li, A., Tong, G. J., et al. (2017). A Cas9-based toolkit to program gene expression in Saccharomyces cerevisiae. Nucleic Acids Res. 45, 496-508. doi: 10.1093/nar/gkw1023

Barton, N. A., Marsh, B. J., Lewis, W., Narraidoo, N., Seymour, G. B., Fray, R., et al. (2016). Accessing low-oxidation state taxanes: is taxadiene-4(5)-epoxide on the Taxol biosynthetic pathway? Chem. Sci. 7, 3102-3107. doi: 10.1039/c5sc03463a

Besumbes, Ó, Sauret-Güeto, S., Phillips, M. A., Imperial, S., RodríguezConcepción, M., and Boronat, A. (2004). Metabolic engineering of isoprenoid biosynthesis in Arabidopsis for the production of taxadiene, the first committed precursor of taxol. Biotechnol. Bioeng. 88, 168-175. doi: 10.1002/bit.20237

Bian, G., Yuan, Y., Tao, H., Shi, X., Zhong, X., Han, Y., et al. (2017). Production of taxadiene by engineering of mevalonate pathway in Escherichia coli and endophytic fungus Alternaria alternata TPF6. Biotechnol. J. 12, 1-11. doi: 10. 1002/biot.201600697

Biggs, B. W., Lim, C. G., Sagliani, K., Shankar, S., Stephanopoulos, G., De Mey, M., et al. (2016a). Overcoming heterologous protein interdependency to optimize P450-mediated Taxol precursor synthesis in Escherichia coli. Proc. Natl. Acad. Sci. U.S.A. 113, 3209-3214. doi: 10.1073/pnas.1515826113

\section{AUTHOR CONTRIBUTIONS}

IM and JL drafted the manuscript with support from FX. IM, $\mathrm{JL}, \mathrm{FX}$, and YW revised the manuscript. YW supervised this work. All authors contributed to the article and approved the submitted version.

\section{FUNDING}

This work was funded by the National Key R\&D Program of China (2018YFA0900600), the National Natural Science Foundation of China (Grant nos. 22077129, 31670099, 31700261, and 41876084) and Research Program of State Key Laboratory of Bioreactor Engineering, the Tianjin Synthetic Biotechnology Innovation Capacity Improvement Project (TSBICIP-KJGG002-15), the Program of Shanghai Academic Research Leader (20XD1404400), the Strategic Priority Research Program "Molecular mechanism of Plant Growth and Development" of CAS (XDB27020202 and XDB27020103), the Construction of the Registry and Database of Bioparts for Synthetic Biology of the Chinese Academy of Sciences (No. ZSYS-016), the International Partnership Program of Chinese Academy of Sciences (No. 153D31KYSB20170121), and the National Key Laboratory of Plant Molecular Genetics, SIPPE, CAS.

Biggs, B. W., Rouck, J. E., Kambalyal, A., Arnold, W., Lim, C. G., De Mey, M., et al. (2016b). Orthogonal assays clarify the oxidative biochemistry of Taxol P450 CYP725A4. ACS Chem. Biol. 11, 1445-1451. doi: 10.1021/acschembio.5b00968

Cha, M., Shim, S. H., Kim, S. H., Kim, O. T., Lee, S. W., Kwon, S. Y., et al. (2012). Production of taxadiene from cultured ginseng roots transformed with Taxadiene synthase gene. BMB Rep. 45, 589-594. doi: 10.5483/BMBRep.2012. 45.10 .085

Choi, H. K., Kim, S. I., Son, J. S., Hong, S. S., Lee, H. S., and Lee, H. J. (2000). Enhancement of paclitaxel production by temperature shift in suspension culture of Taxus chinensis. Enzyme Microb. Technol. 27, 593-598. doi: 10.1016/ S0141-0229(00)00255-6

De La Peña, R., and Sattely, E. S. (2020). Rerouting plant terpene biosynthesis enables momilactone pathway elucidation. Nat. Chem. Biol. 17, 205-212. doi: 10.1038/s41589-020-00669-3

DeJong, J. H. M., Liu, Y., Bollon, A. P., Long, R. M., Jennewein, S., Williams, D., et al. (2006). Genetic engineering of taxol biosynthetic genes in Saccharomyces cerevisiae. Biotechnol. Bioeng. 93, 212-224. doi: 10.1002/bit.20694

Ding, M. Z., Yan, H. F., Li, L. F., Zhai, F., Shang, L. Q., Yin, Z., et al. (2014). Biosynthesis of taxadiene in Saccharomyces cerevisiae: selection of geranylgeranyl diphosphate synthase directed by a computer-aided docking strategy. PLoS One 9:e0109348. doi: 10.1371/journal.pone.0109348

Edgar, S., Li, F. S., Qiao, K., Weng, J. K., and Stephanopoulos, G. (2017). Engineering of Taxadiene synthase for improved selectivity and yield of a key taxol biosynthetic intermediate. ACS Synth. Biol. 6, 201-205. doi: 10.1021/ acssynbio.6b00206

Edgar, S., Zhou, K., Qiao, K., King, J. R., Simpson, J. H., and Stephanopoulos, G. (2016). Mechanistic insights into Taxadiene epoxidation by taxadiene- $5 \alpha-$ hydroxylase. ACS Chem. Biol. 11, 460-469. doi: 10.1021/acschembio.5b00767

Engels, B., Dahm, P., and Jennewein, S. (2008). Metabolic engineering of taxadiene biosynthesis in yeast as a first step towards Taxol (Paclitaxel) production. Metab. Eng. 10, 201-206. doi: 10.1016/j.ymben.2008.03.001

Escorcia, A. M., van Rijn, J. P. M., Cheng, G. J., Schrepfer, P., Brück, T. B., and Thiel, W. (2018). Molecular dynamics study of Taxadiene synthase catalysis. J. Comput. Chem. 39, 1215-1225. doi: 10.1002/jcc.25184 
Fett-Netto, A. G., DiCosmo, F., Reynolds, W. F., and Sakata, K. (1992). Cell culture of Taxus as a source of the antineoplastic drug taxol and related taxanes. Nat. B 10, 1572-1575. doi: 10.1038/nbt1292-1572

Freud, Y., Ansbacher, T., and Major, D. T. (2017). Catalytic control in the facile proton transfer in Taxadiene synthase. ACS Catal. 7, 7653-7657. doi: 10.1021/ acscatal.7b02824

Glasscock, C. J., Lazar, J. T., Biggs, B. W., Arnold, J. H., Kang, M. K., Tullman-ercek, D., et al. (2019). Dynamic control of pathway expression with riboregulated switchable feedback promoters. bioRxiv [Preprint]. doi: 10.1101/529180

Gutta, P., and Tantillo, D. J. (2007). A promiscuous proton in taxadiene biosynthesis? Org. Lett. 9, 1069-1071. doi: 10.1021/ol070007m

He, C. T., Li, Z. L., Zhou, Q., Shen, C., Huang, Y. Y., Mubeen, S., et al. (2018). Transcriptome profiling reveals specific patterns of paclitaxel synthesis in a new Taxus yunnanensis cultivar. Plant Physiol. Biochem. 122, 10-18. doi: 10.1016/j. plaphy.2017.10.028

Hefner, J., Rubenstein, S. M., Ketchum, R. E. B., Gibson, D. M., Williams, R. M., and Croteau, R. (1996). Cytochrome P450-catalyzed hydroxylation of taxa4(5),11(12)-diene to taxa-4(20),11(12)-dien-5a-ol: the first oxygenation step in taxol biosynthesis. Chem. Biol. 3, 479-489. doi: 10.1016/S1074-5521(96)900964

Hezari, M., Lewis, N. G., and Croteau, R. (1995). Purification and Characterization of Taxa-4(5),11(12)-diene synthase from Pacific yew (Taxus brevifolia) that catalyzes the first committed step of Taxol biosynthesis. Arch. Biochem. Biophys. 322, 437-444.

Holton, R. A., Somoza, C., Kim, H. B., Liang, F., Biediger, R. J., Boatman, P. D., et al. (1994). First total synthesis of taxol. 1. Functionalization of the B ring. J. Am. Chem. Soc. 116, 1597-1598. doi: 10.1021/ja00083a066

Hong, Y. J., and Tantillo, D. J. (2011). The taxadiene-forming carbocation cascade. J. Am. Chem. Soc. 133, 18249-18256. doi: 10.1021/ja2055929

Huang, Q., Roessner, C. A., Croteaul, R., Scott, A. I., Huang, Q. L., and Roessner, C. (2001). Engineering Escherichia coli for the synthesis of taxadiene. Bioorgan. Med. Chem. 9, 2237-2242.

Jennewein, S., Long, R. M., Williams, R. M., and Croteau, R. (2004). Cytochrome P450 taxadiene 5a-hydroxylase, a mechanistically unusual monooxygenase catalyzing the first oxygenation step of taxol biosynthesis. Chem. Biol. 11, 379-387. doi: 10.1016/j

Jennewein, S., Rithner, C. D., Williams, R. M., and Croteau, R. B. (2001). Taxol biosynthesis: taxane 13 alpha-hydroxylase is a cytochrome P450-dependent monooxygenase. Proc. Natl. Acad. Sci. U.S.A. 98, 13595-13600. doi: 10.1073/ pnas. 251539398

Kaspera, R., and Croteau, R. (2006). Cytochrome P450 oxygenases of taxol biosynthesis. Phytochem. Rev. 5, 433-444. doi: 10.1007/s11101-006-9006-4

Kaspera, R., Croteau, R., Rodney, C., and Kaspera, R. (2006). Cytochrome P450 oxygenases of taxol biosynthesis. Phytochem. Rev. 5, 433-444.

Ketchum, R. E. B., and Croteau, R. B. (2006). The Taxus metabolome and the elucidation of the $\operatorname{taxol}^{\circledR}$ biosynthetic pathway in cell suspension cultures. Biotechnol. Agric. Forest 57, 291-309. doi: 10.1007/3-540-297 82-0_21

Koepp, A. E., Hezari, M., Zajicek, J., Vogel, B. S., LaFever, R. E., Lewis, N. G., et al. (1995). Cyclization of geranylgeranyl diphosphate to taxa-4(5),11(12)-diene is the committed step of taxol biosynthesis in Pacific yew. J. Biol. Chem. 270, 8686-8690. doi: 10.1074/JBC.270.15.8686

Köksal, M., Jin, Y., Coates, R. M., Croteau, R., and Christianson, D. W. (2011). Taxadiene synthase structure and evolution of modular architecture in terpene biosynthesis. Nature 469, 116-122. doi: 10.1038/nature09628

Kovacs, K., Zhang, L., Linforth, R. S. T., Whittaker, B., Hayes, C. J., and Fray, R. G. (2007). Redirection of carotenoid metabolism for the efficient production of taxadiene [taxa-4(5),11(12)-diene] in transgenic tomato fruit. Transgen. Res. 16, 121-126. doi: 10.1007/s11248-006-9039-x

Kuang, X., Sun, S., Wei, J., Li, Y., and Sun, C. (2019). Iso-Seq analysis of the Taxus cuspidata transcriptome reveals the complexity of Taxol biosynthesis. BMC Plant Biol. 19:210. doi: 10.1186/s12870-019-1809-8

Lenka, S. K., Nims, N. E., Vongpaseuth, K., Boshar, R. A., Roberts, S. C., and Walker, E. L. (2015). Jasmonate-responsive expression of paclitaxel biosynthesis genes in Taxus cuspidata cultured cells is negatively regulated by the bHLH transcription factors TcJAMYC1, TcJAMYC2, and TcJAMYC4. Front. Plant Sci. 6:115. doi: 10.3389/fpls.2015.00115
Li, B. J., Wang, H., Gong, T., Chen, J. J., Chen, T. J., Yang, J. L., et al. (2017). Improving 10-deacetylbaccatin III-10- $\beta$-O-acetyltransferase catalytic fitness for Taxol production. Nat. Commun. 8, 1-13. doi: 10.1038/ncomms15544

Li, J., Mutanda, I., Wang, K., Yang, L., Wang, J., and Wang, Y. (2019). Chloroplastic metabolic engineering coupled with isoprenoid pool enhancement for committed taxanes biosynthesis in Nicotiana benthamiana. Nat. Commun. 10, 1-12. doi: 10.1038/s41467-019-12879-y

Liao, W., Zhao, S., Zhang, M., Dong, K., Chen, Y., Fu, C., et al. (2017). Transcriptome assembly and systematic identification of novel cytochrome P450s in Taxus chinensis. Front. Plant Sci. 8:1468. doi: 10.3389/fpls.2017.01468

Lin, S. L., Wei, T., Lin, J. F., Guo, L. Q., Wu, G. P., Wei, J., et al. (2018). Bio-production of Baccatin III, an important precursor of paclitaxel by a costeffective approach. Mol. Biotechnol. 60, 492-505. doi: 10.1007/s12033-0180090-7

Lin, X., Hezari, M., Koepp, A. E., Floss, H. G., and Croteau, R. (1996). Mechanism of taxadiene synthase, a diterpene cyclase that catalyzes the first step of taxol biosynthesis in Pacific yew. Biochemistry 35, 2968-2977. doi: 10.1021/ bi9526239

Malik, S., Cusidó, R. M., Mirjalili, M. H., Moyano, E., Palazón, J., and Bonfill, M. (2011). Production of the anticancer drug taxol in Taxus baccata suspension cultures: a review. Process Biochem. 46, 23-34. doi: 10.1016/j.procbio.2010.09. 004

Mao, R., Chen, J., Chen, Y., and Guo, Z. (2018). Identification of early jasmonateresponsive genes in Taxus $\times$ media cells by analyzing time series digital gene expression data. Physiol. Mol. Biol. Plants 24, 715-727. doi: 10.1007/s12298018-0527-2

McElroy, C., and Jennewein, S. (2017). "Taxol ${ }^{\circledR}$ biosynthesis and production: from forests to fermenters," in Biotechnology of Natural Products, eds W. Schwab, B. Lange, and M. Wüst (Cham: Springer), 145-185. doi: 10.1007/978-3-31967903-7_7

Miao, L. Y., Mo, X. C., Xi, X. Y., Zhou, L., De, G., Ke, Y. S., et al. (2018). Transcriptome analysis of a taxol-producing endophytic fungus Cladosporium cladosporioides MD2. AMB Express 8:41. doi: 10.1186/s13568-018-0567-6

Mountford, P. G. (2010). "The Taxol ${ }^{\circledR}$ story - development of a green synthesis via plant," in Green Chemistry in the Pharmaceutical Industry, eds P. J. Dunn, A. S. Wells, and M. T. Williams (Weinheim: Wiley-VCH Verlag GmbH \& Co), $145-160$.

Nicolaou, K. C., Yang, Z., Liu, J. J., Ueno, H., Nantermet, P. G., Guy, R. K., et al. (1994). Total synthesis of taxol. Nature 367, 630-634. doi: 10.1038/367630a0

Nowrouzi, B., Li, R., Walls, L. E., D’Espaux, L., Malci, K., Lungang, L., et al. (2020). Enhanced production of taxadiene in Saccharomyces cerevisiae. Microb. Cell Fact 19:200.

Ramírez-Estrada, K., Altabella, T., Onrubia, M., Moyano, E., Notredame, C., Osuna, L., et al. (2016). Transcript profiling of jasmonate-elicited Taxus cells reveals a $\beta$-phenylalanine-CoA ligase. Plant Biotechnol. J. 14, 85-96. doi: 10. 1111/pbi.12359

Rontein, D., Onillon, S., Herbette, G., Lesot, A., Werck-Reichhart, D., Sallaud, C., et al. (2008). CYP725A4 from yew catalyzes complex structural rearrangement of taxa-4(5),11(12)-diene into the cyclic ether 5(12)-oxa-3(11)-cyclotaxane. J. Biol. Chem. 283, 6067-6075. doi: 10.1074/jbc.M708950200

Rouck, J. E., Biggs, B. W., Kambalyal, A., Arnold, W. R., De Mey, M., Ajikumar, P. K., et al. (2017). Heterologous expression and characterization of plant Taxadiene-5 $\alpha$-Hydroxylase (CYP725A4) in Escherichia coli. Protein Expr. Purif. 132, 60-67. doi: 10.1016/j.pep.2017.01.008

Sagwan-Barkdoll, L., and Anterola, A. M. (2017). Taxadiene- $5 \alpha-$ ol is a minor product of CYP725A4 when expressed in Escherichia coli. Biotechnol. Appl. Biochem. 65, 294-305. doi: 10.1002/bab.1606

Sanchez-Muñoz, R., Perez-Mata, E., Almagro, L., Cusido, R. M., Bonfill, M., Palazon, J., et al. (2020). A novel hydroxylation step in the Taxane biosynthetic pathway: a new approach to Paclitaxel production by synthetic biology. Front. Bioeng. Biotechnol. 8:410. doi: 10.3389/fbioe.2020.00410

Schoendorf, A., Rithner, C. D., Williams, R. M., and Croteau, R. B. (2001). Molecular cloning of a cytochrome P450 taxane 10 $\beta$-hydroxylase cDNA from Taxus and functional expression in yeast. Proc. Natl. Acad. Sci. U.S.A. 98, 1501-1506. doi: 10.1073/pnas.98.4.1501

Schrepfer, P., Buettner, A., Goerner, C., Hertel, M., Rijn, J., Van Wallrapp, F., et al. (2016). Identification of amino acid networks governing catalysis in the 
closed complex of class I Terpene synthases. Proc. Natl. Acad. Sci. U.S.A. 113, E958-E967. doi: 10.1073/pnas.1519680113

Srividya, N., Lange, I., Hartmann, M., Li, Q., Mirzaei, M., and Lange, B. M. (2020). Biochemical characterization of acyl activating enzymes for side chain moieties of Taxol and its analogs. J. Biol. Chem. 295, 4963-4973. doi: 10.1074/jbc.RA120. 012663

van Rijn, J. P. M., Escorcia, A. M., and Thiel, W. (2019). QM/MM study of the Taxadiene synthase mechanism. J. Comput. Chem. 40, 1902-1910. doi: 10.1002/ jcc. 25846

Vogl, T., Kickenweiz, T., Pitzer, J., Sturmberger, L., Weninger, A., Biggs, B. W., et al. (2018). Engineered bidirectional promoters enable rapid multi-gene co-expression optimization. Nat. Commun. 9:3589. doi: 10.1038/s41467-01805915-w

Walker, K., and Croteau, R. (2001). Taxol biosynthetic genes. Phytochemistry 58, 1-7. doi: 10.1016/S0031-9422(01)00160-1

Walker, K., Schoendorf, A., and Croteau, R. (2000). Molecular cloning of a taxa4(20),11(12)-dien-5 $\alpha$-ol-O-acetyl transferase cDNA from Taxus and functional expression in Escherichia coli. Arch. Biochem. Biophys. 374, 371-380. doi: 10. 1006/abbi.1999.1609

Wani, M. C., and Horwitz, S. B. (2014). Nature as a remarkable chemist: a personal story of the discovery and development of Taxol. Anticancer. Drugs 25, 482-487. doi: 10.1097/CAD.0000000000000063

Wani, M. C., Taylor, H. L., Wall, M. E., Coggon, P., and Mcphail, A. T. (1971). Plant antitumor agents.VI. The isolation and structure of Taxol, a novel antileukemic and antitumor agent from Taxus brevifolia2. J. Am. Chem. Soc. 93, 2325-2327. doi: $10.1021 /$ ja00738a045

Wildung, M. R., and Croteau, R. (1996). A cDNA clone for taxadiene synthase, the diterpene cyclase that catalyzes the committed step of taxol biosynthesis. J. Biol. Chem. 271, 9201-9204. doi: 10.1074/jbc.271.16.9201

Williams, D. C., Carroll, B. J., Jin, Q., Rithner, C. D., Lenger, S. R., Floss, H. G., et al. (2000a). Intramolecular proton transfer in the cyclization of geranylgeranyl diphosphate to the taxadiene precursor of taxol catalyzed by recombinant Taxadiene synthase. Chem. Biol. 7, 969-977. doi: 10.1016/S10745521(00)00046-6

Williams, D. C., Wildung, M. R., Jin, A. Q., Dalal, D., Oliver, J. S., Coates, R. M., et al. (2000b). Heterologous expression and characterization of a "Pseudomature" form of Taxadiene synthase involved in paclitaxel (Taxol) biosynthesis and evaluation of a potential intermediate and inhibitors of the Multistep Diterpene Cyclization reaction. Arch. Biochem. Biophys. 379, 137146. doi: 10.1006/abbi.2000.1865

Yadav, V. G. (2014). Unraveling the multispecificity and catalytic promiscuity of taxadiene monooxygenase. J. Mol. Catal. B Enzym. 110, 154-164. doi: 10.1016/ j.molcatb.2014.10.004

You, L. F., Huang, J. J., Wei, T., Lin, S. L., Jiang, B. H., Guo, L. Q., et al. (2018). Enhanced catalytic activities and modified substrate preferences for taxoid $10 \beta$-O-acetyl transferase mutants by engineering catalytic histidine residues. Biotechnol. Lett. 40, 1245-1251. doi: 10.1007/s10529-018-2573-9

Zhang, M., Chen, Y., Nie, L., Jin, X., Liao, W., Zhao, S., et al. (2018a). Transcriptome-wide identification and screening of WRKY factors involved in the regulation of taxol biosynthesis in Taxus chinensis. Sci. Rep. 8, 1-12. doi: 10.1038/s41598-018-23558-1

Zhang, M., Jin, X., Chen, Y., Wei, M., Liao, W., Zhao, S., et al. (2018b). TcMYC2a, a basic helix-loop-helix transcription factor, transduces JA-signals and regulates taxol biosynthesis in Taxus chinensis. Front. Plant Sci. 9:863. doi: 10.3389/fpls. 2018.00863

Zhou, K., Qiao, K., Edgar, S., and Stephanopoulos, G. (2015). Distributing a metabolic pathway among a microbial consortium enhances production of natural products. Nat. Biotechnol. 33, 377-383. doi: 10.1038/nbt.3095

Zhou, T., Luo, X., Yu, C., Zhang, C., Zhang, L., Song, Y. B., et al. (2019). Transcriptome analyses provide insights into the expression pattern and sequence similarity of several taxol biosynthesis-related genes in three Taxus species. BMC Plant Biol. 19:33. doi: 10.1186/s12870-0191645-x

Conflict of Interest: The authors declare that the research was conducted in the absence of any commercial or financial relationships that could be construed as a potential conflict of interest.

Copyright (c) 2021 Mutanda, Li, Xu and Wang. This is an open-access article distributed under the terms of the Creative Commons Attribution License (CC BY). The use, distribution or reproduction in other forums is permitted, provided the original author(s) and the copyright owner(s) are credited and that the original publication in this journal is cited, in accordance with accepted academic practice. No use, distribution or reproduction is permitted which does not comply with these terms. 